\title{
Evaluation of Five Electronic Apex Locators Accuracy in Determining the Major Foramen and Apical Constriction: An in vitro study
}

Emma Hunter

Follow this and additional works at: https://researchrepository.wvu.edu/etd

\section{Recommended Citation}

Hunter, Emma, "Evaluation of Five Electronic Apex Locators Accuracy in Determining the Major Foramen and Apical Constriction: An in vitro study" (2016). Graduate Theses, Dissertations, and Problem Reports. 5843.

https://researchrepository.wvu.edu/etd/5843

This Thesis is protected by copyright and/or related rights. It has been brought to you by the The Research Repository @ WVU with permission from the rights-holder(s). You are free to use this Thesis in any way that is permitted by the copyright and related rights legislation that applies to your use. For other uses you must obtain permission from the rights-holder(s) directly, unless additional rights are indicated by a Creative Commons license in the record and/ or on the work itself. This Thesis has been accepted for inclusion in WVU Graduate Theses, Dissertations, and Problem Reports collection by an authorized administrator of The Research Repository @ WVU. For more information, please contact researchrepository@mail.wvu.edu. 


\section{Evaluation of Five Electronic Apex Locators Accuracy in Determining the Major Foramen and Apical Constriction: an in vitro study}

\section{Emma Hunter, DDS}

Thesis Submitted to the School of Dentistry of Robert C. Byrd Health Sciences Center at West Virginia University in partial fulfillment of the requirements for the degree of

Master of Science in Endodontics

Richard Jurevic, DDS, PhD, MsD

Michael Bagby, DDS, PhD, MS

L. Keith Hildebrand, DDS, MS

Department of Endodontics

Morgantown, West Virginia

2016

Keywords: Dental, Endodontics, Electronic Apex Locator, Working Length, Apical Constriction

Copyright 2016 Emma Hunter D.D.S 


\begin{abstract}
Evaluation of Five Electronic Apex Locators Accuracy in Determining the Major Foramen and Reliability of Indication of the Apical Constriction: an in vitro study
\end{abstract}

Emma Hunter, D.D.S.

\begin{abstract}
AIM:
The purpose of this study was to compare the diagnostic accuracy of five different electronic apex locators (EAL), including the Root ZX II, Endo-EZE FIND, APEX ID, ProMark, and Parkell Formatron. The evaluation of the EALs were two-fold. One objective was to evaluate the ability of each EAL to detect the major foramen, and the second objective was to evaluate the reliability of each EAL indication of the apical constriction.

\section{Materials and Methods:}

A total of 100 single-canal extracted human teeth were decoronated and checked for patency. Fifty teeth were evaluated by each electronic apex locator to determine their accuracy for locating the major foramen. The teeth were embedded in alginate. A \#15 K-file was advanced in each canal until the major foramen indicator was reached on their screen. The remaining 50 teeth were randomly assigned to five groups $(n=10)$. Each group was assessed by a single EAL. A \#15 K-file was advanced until the major foramen was reached and then retreated slowly until the apical constriction indicator was achieved on the EAL's screen. The file was then cemented in place, with the apical $5 \mathrm{~mm}$ of the tooth sectioned longitudinally until the file was exposed. The distance from the file tip to the major foramen was measured.
\end{abstract}

\title{
Results:
}

Statistical results showed a significant difference between the five EALs in their ability to accurately identify the major foramen, as found by a repeated-measures ANOVA $(\mathrm{p}<0.0001)$. A Tukey's Standardized Range Test found the Apex ID and Root ZX II to have significantly lower mean measurements $(\mathrm{mm})$ from the file tip at the major foramen indicator to the major foramen. However, when analyzing the distances $(\mathrm{mm})$ from the file tip to the "apical constriction" indicator to the major foramen, there was no significant difference found between the respective EAL groups, as determined by Kruskal-Wallis test. 


\section{Conclusions:}

The Apex ID and Root ZX II were more accurate in their location of the major foramen. All five EALs preformed within the same level of consistency in their indication of an apical constriction. The Apex ID location of the apical constriction resulted in no overextension of the file tip beyond the major foramen. 


\section{Dedication}

To my companion and best friend: Thank you for your support over the past decade of my life, especially through these long years of dental school and endodontic residency. Thank you for being a wonderful dad (and stand in mom) to our beautiful children.

To my parents: As I have grown older and wiser, I realize how blessed I was to be raised by such kind and compassionate people. You have always given all and more to your family. Thank you for your examples of love and fidelity and your dedication and partnership in your roles as mother and father. Every achievement in my life, I can trace back to my early education and exposure to discipline and hard work in our family home.

To my beautiful children: You three are my motivation in life. Words can never express the joy that you bring me. Thank you for your kisses and giggles over the last two years. 


\section{Acknowledgements}

Dr. Speer: Thank you for your mentorship over the last year. I've appreciated your guidance in efficiency and patient management.

Dr. Hildebrand: Thank you for allowing me to vent and express my feelings $(;)$ I have appreciated your patience and understanding

Dr. Borgia: I would not be in the program if it was not for your assistance with the application procedure and your enthusiasm for endodontics when I was a student.

Dr. Bagby: Thanks for your encouragement with my research, and prodding to get it down.

Dr. Jurevic: Thanks for your encouragement and use of the digital caliber with my research project.

Dr. Wisam Sakr: We have seen a lot through our two years here! It was a fun time with lots of giggles and tears (all from me). Thanks for looking past my moods.

Dr. Pejman Parsa: Your endless sarcasm pulled me through the first year! Thanks for helping me develop thick skin. You taught me to never settle for just okay.

Dr. Andy Xu: You definitely were my endodontic big brother! I feel like I learned a lot from you about endodontics and life. I am so grateful to have had you as a second year.

Dr. Stephen Fragale: I could not have asked for a better first year resident! You are such a hard worker and curious about everything - which has made you a wonderful clinician! Good luck next year (and the year after)....

Dr. Sean Horan: It has been great having you as a first year resident. Your exactness and dedication is amazing. Please keep Stephen (and the rest) in line next year!

Mr. Mehran Malakpour: I truly appreciate all of the time you sacrificed to help me with my research! Thank you so much. I hope we stay connected and look forward to endodontic conversations for years to come.

Mr. Patrick Cushing: Thanks for all your work and guidance with the statistics.

Thank you to all the faculty and staff at WVU for supporting the Endodontic Department 


\section{Table of Contents}

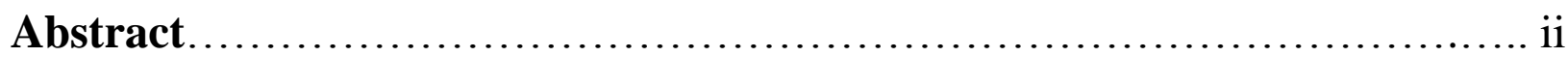

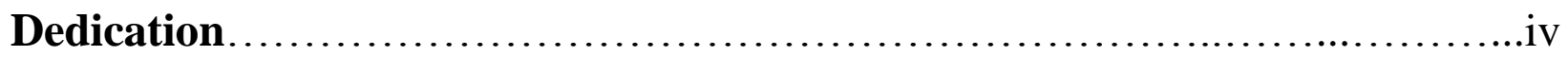

Acknowledgments.........................................................

Table of Contents ..............................................................

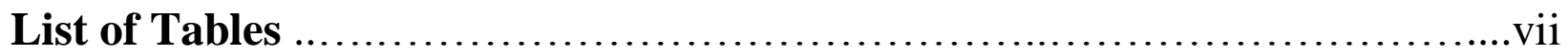

List of Figures ..................................................... viii

List of Symbols, Abbreviation, or Nomenclature ..........................ix

Chapter 1:

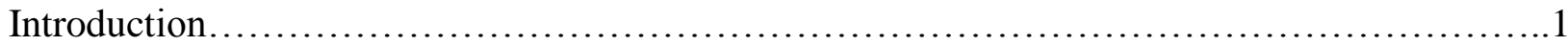

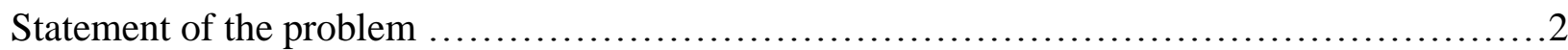

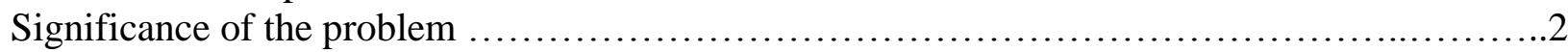

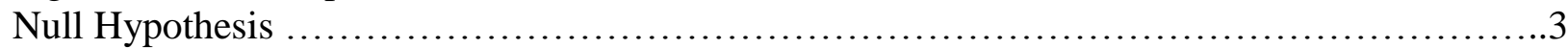

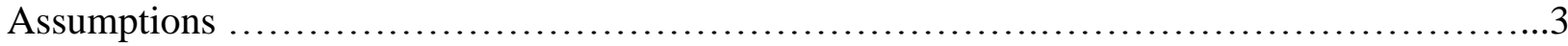

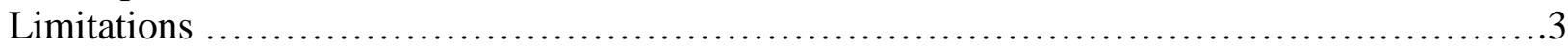

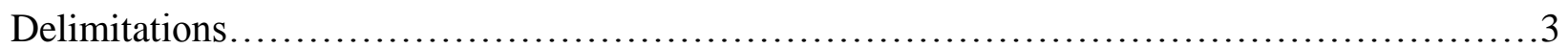

\section{Chapter 2:}

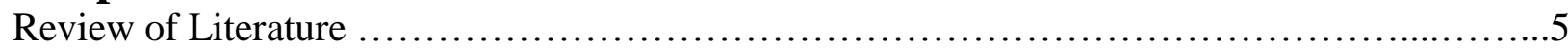

\section{Chapter 3:}

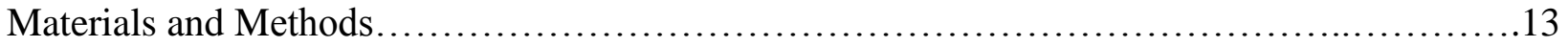

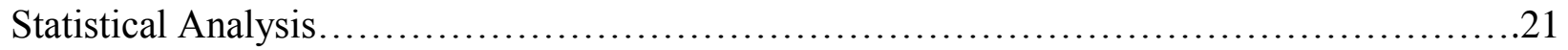

\section{Chapter 4}

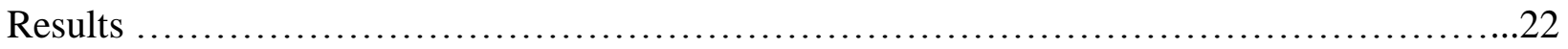

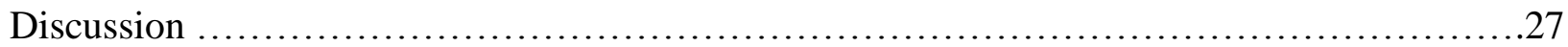

\section{Chapter 5}

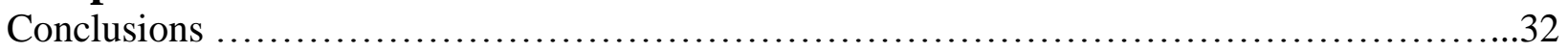

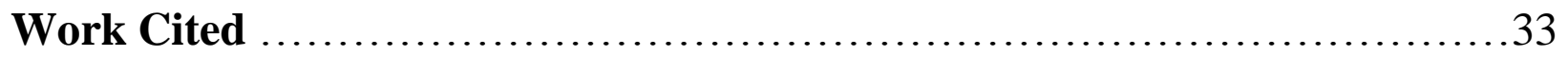




\section{Appendix}

Difference between the control length and the PL per EAL device............................39

Measurement from AC indicator to MF.................................................. 40 


\section{List of Tables}

Table 1. Difference $(\mathrm{mm})$ per EAL between the PL and MF indicator.......................23

Table 2. Distance ( $\mathrm{mm}$ ) from the file tip to the MF according to AC indicator................25

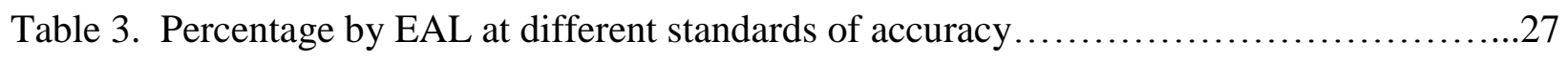

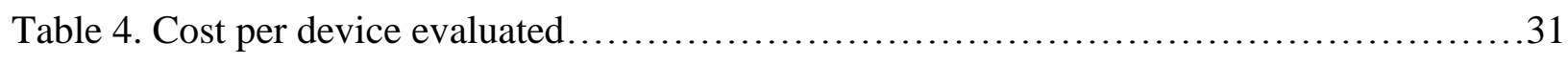




\section{List of Figures}

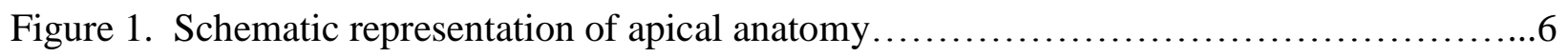

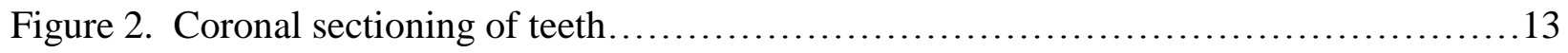

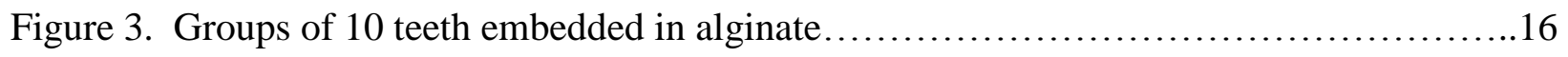

Figure 4. File cemented in place with last $5 \mathrm{~mm}$ sectioned with file exposed....................16

Figure 5. Measurement from file tip at designated "AC" to MF.............................. 17

Figure 6. Apex ID indicator screen indicating that the MF has been reached....................18

Figure 7. Apex ID indicator screen indicating that the AC has been reached...................18

Figure 8. Endo-Eze Find indicator screen indicating that the MF has been reached..............19

Figure 9. Endo-Eze Find indicator screen indicating that the $\mathrm{AC}$ has been reached.............19

Figure 10. Foramatron indicator screen indicating that the MF has been reached................19

Figure 11. Foramatron indicator screen indicating that the $\mathrm{AC}$ has been reached................19

Figure 12. ProMARK indicator screen indicating that the MF has been reached................20

Figure 13. ProMARK indicator screen indicating that the $\mathrm{AC}$ has been reached................20

Figure 14. Root ZX II indicator screen indicating that the MF has been reached................20

Figure 15. Root ZX II indicator screen indicating that the AC has been reached................20

Figure 16. Distance from the PL to the control length as measured with each respective MF

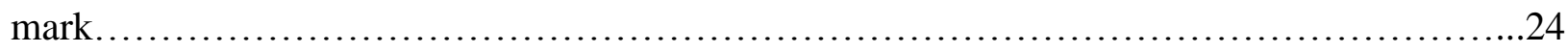

Figure 17. Distance from the file tip to AC as measured with each respective EAL.............26 


\section{List of Symbols, Abbreviation, or Nomenclature}

Root Canal System - RCS - the space containing the dental pulp inside the crown and root of a tooth

Working length $-\mathrm{WL}$ - the distance from a coronal reference point to the point at which canal preparation and obturation should terminate

Apical Constriction - AC - the apical portion of the root canal having the narrowest diameter; position may vary but is usually $0.5-1.0 \mathrm{~mm}$ short of the center of the major foramen Electronic Apex Locator - EAL - an electronic instrument used to assist in determining the root canal working length or perforation; operates on the principles of resistance, frequency or impedance

Major Foramen - MF - the main apical opening of the root canal

Cementodentinal Junction - CDJ - the region at which the dentin and cementum are united; commonly used to denote the point at which the cemental surface terminates at or near the apex of a tooth; histological landmark, and can range $0.5-3.0 \mathrm{~mm}$ short of anatomic apex Root Canal Therapy - RCT - sequence of treatment for the infected pulp of a tooth which results in the elimination of infection and the protection of the decontaminated tooth from future microbial invasion

Anatomical Apex - the tip or end of the root as determined morphologically

Radiographic Apex - the tip or end of the root as determined radiographically; its location can vary from the anatomic apex due to root morphology and distribution of the radiographic image Control length - the length of the RCS in $\mathrm{mm}$ as determined by measurement from a coronal reference point to the point at which a \#15 $\mathrm{k}$ file is just visible under a dental operating microscope with $0.5 \mathrm{~mm}$ subtracted 
Physiological length (EAL) - PL - the length of the RCS in mm as determined by measurement from a coronal reference point to the point at which a \#15 k file reaches the MF as indicated by the indicator screen of an EAL 


\section{Chapter 1}

\section{Introduction}

The prevailing factor that influences root canal therapy success or failure is eradication of microorganisms to the greatest extent possible within the root canal system (RCS). Determining an accurate working length (WL), is an essential step in the process of root canal debridement. Working length, measured in millimeters, is a reproducible measurement from a coronal reference point where apical cleaning, shaping, and obturation should end. ${ }^{1}$ An accurate working length ensures maintenance of the root canal system's integrity and proper disinfection and obturation. $^{2}$

It has been proposed that the working length should conclude at the apical constriction (AC). ${ }^{3}$ The American Association of Endodontists Glossary of Endodontic Terms describes this as the "apical portion of the root canal having the narrowest diameter; position may vary but is usually $0.5 \mathrm{~mm}-1.0 \mathrm{~mm}$ short of the center of the apical foramen". ${ }^{1}$ This anatomical area has been stated to provide the best opportunity for periapical healing, as it minimizes the infringement upon the periapical tissues. A working length in excess of the apical constriction can lead to overextension of obturation materials and potentially increased post-operative pain or delayed healing. A working length short of the apical constriction can contribute to persistent infection due to remaining microorganisms in an inadequately cleaned and shaped RCS. ${ }^{4}$ However, as found by Dummer et al, many RCS do not have a distinct AC but this anatomical landmark may be more conceptual than a tangible position. ${ }^{5}$ Previous emphasis and research assumptions of the $\mathrm{AC}$ as a set point may be clinically irrelevant, while emphasizing remaining within the RCS as a basis for clinical evaluation, may be indicated. ${ }^{6}$ 
Working length determination has traditionally been determined through radiographic determination, and/or with electronic apex locators (EAL). With the introduction of the use of EALs beginning in 1962 with Sunada's research on the electrical resistance between the oral mucosa and the RCS, the historical practice of working length determination by only radiographic means has become increasing rudimentary. ${ }^{7}$ Electronic apex locators have been shown to be more accurate than radiography at determining the working length. ${ }^{8}$

The purpose of this study was to compare the ability of five EALs to accurately determine the major foramen (MF) and the reliability of each EAL's indication of the AC, within an anatomical area coronal to the MF.

\section{Statement of the Problem}

Do the five electronic apex locators accurately determine the major foramen and apical constriction? The electronic apex locators studied were the Apex ID (Kerr Dental Co, Orange, CA), Endo-Eze FIND (Ultradent Products Inc, South Jordan, UT), Foramatron (Parkell Inc, Edgewood, NY), ProMARK (Dentsply, York, PA), and Root ZX II (J Morita CO, Tokyo, Japan).

\section{Significance of the Problem}

This study will provide an in vitro comparison of some of the currently most widely used EALs. This will give a basis for each individual EAL's ability to locate the major foramen and the reliability of each EAL location of the apical constriction as designated by the indicator screen. 


\section{Null Hypothesis}

There is no statistically significant difference between the Apex ID, Endo-Eze FIND, Foramatron, ProMARK, and Root ZX II ability to locate the major foramen and ability to reliably depict the apical constriction, as determined by the indicator screen and confirmed under microscopic evaluation.

\section{Assumptions}

1. Obturation should be contained within the root canal system.

2. The apical constriction should be used for working length termination.

3. Alginate provides an acceptable medium for determination of working length in vitro.

4. Microscopic evaluation of physiological length is an accurate way to determine the physiological length.

5. Sectioning the apical $5 \mathrm{~mm}$ with a diamond bur to uncover the file allows for accurate measurements from the file tip to the major foramen.

\section{Limitations}

1. This is an in vitro study of a clinical procedure; therefore, the results may not correlate to an in vivo condition.

2. Apical anatomical variations will exist between the teeth.

3. Small sample size.

\section{Delimitations}

1. Selected teeth were limited to single straight canals.

2. Only roots that exhibited completely formed apices, no signs of resorption, and were patent with a 08 size K-type file were included in the study. 
3. Evaluation of the major foramen utilized the dental operating microscope using $12.8 \mathrm{x}$ magnification (Global Surgical Corp, St. Louis, MO).

4. Teeth were decoronated and reliable stops were made.

5. All measurements were performed by the principal investigator. 


\section{Chapter 2}

\section{Review of the Literature}

The apical third of the RCS is the most highly studied area. Kuttler in 1955 identified an area of smaller diameter, the apical constriction, which he found to be on average $0.59 \mathrm{~mm}$ from the MF, with variations depending on the maturation or age of the tooth. ${ }^{9}$ Dummer in 1984 , found the $\mathrm{AC}$ to be on average $0.89 \mathrm{~mm}$ away from the anatomical apex, and classified four different types of apical constrictions. ${ }^{5}$ More recent analysis have been performed with microCT. An analysis of palatal canals of first maxillary molars found it was difficult to identify the constriction, and was identified in only $38 \%$ of the time. ${ }^{10}$ ElAyouti found that the majority of AC were parallel, or had a similar diameter for greater than $2.5 \mathrm{~mm}$. He also found that the mean distance from the $\mathrm{AC}$ to the MF was $0.2 \mathrm{~mm} .{ }^{11}$

Historically, the apical limit of root canal cleaning and shaping and obturation has been greatly contested. Many authors have expounded further on this research and developed guidelines as to the apical limit of RCT based off Kuttler's findings. Weine indicated that the point of termination should be the apical constriction, which he believed to correspond to the location of the cementodentinal junction (CDJ). ${ }^{12}$ The CDJ is the region at which the dentin and cementum are united; commonly used to denote the point at which the cemental surface terminates at or near the apex of the tooth. ${ }^{1}$ He advocated a location $1 \mathrm{~mm}$ coronal to the radiographic apex as an acceptable point for canal preparation to end. ${ }^{12}$

Like Weine, Ingle also stated that the apical constriction was located at the CDJ, but that this point was located approximately $0.5 \mathrm{~mm}$ coronal to the radiographic apex. Obturation to the radiographic apex was considered to actually be an over-extension. ${ }^{4}$ 
The term "apical stop" was introduced by Frank et al. as the apical limit of the instrumentation, which should be located $0.5 \mathrm{~mm}$ to $1.0 \mathrm{~mm}$ from the apex. This stop would prevent material from extruding out the canal. All of the previously mentioned authors did not place much importance on accessory canals, but focused on the main canal as the source of infection and bacteria. ${ }^{4}$ Langeland showed histologically that the pulp within these lateral canals can remain vital, even when there is a radiolucency. ${ }^{13,14} \mathrm{He}$ also found that the CDJ could be highly variable and was a histopathologic location that could be located up to $3.0 \mathrm{~mm}$ higher on one side of the RCS than the other. This position did also not coincide with the AC. He advocated termination of RCT at the apical constriction regardless of the pulp status. ${ }^{13}$

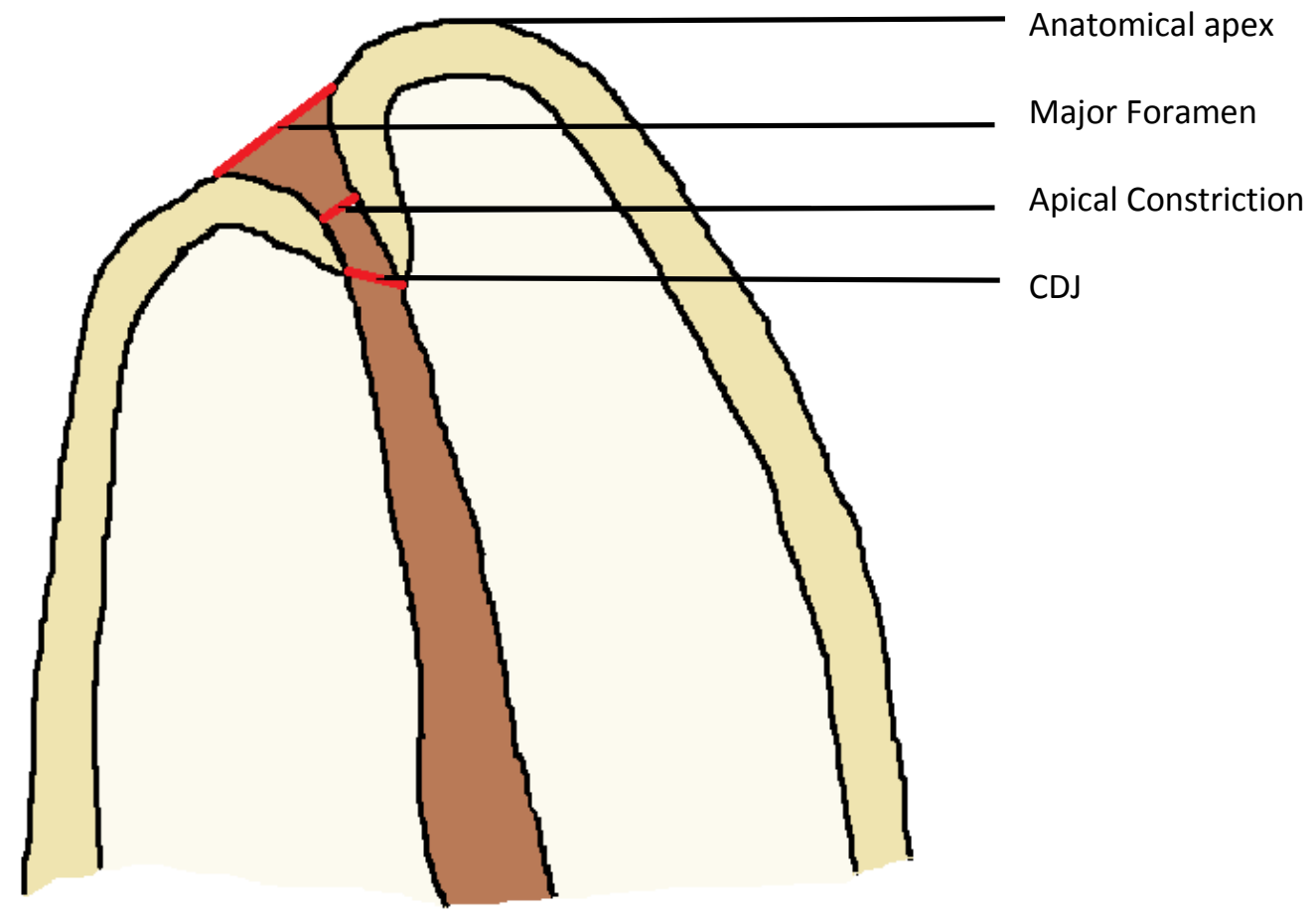

Figure 1: Schematic representation of apical anatomy 
Schilder felt that it was important to debride and fill the entire root canal length. He advocated ending instrumentation and obturation at the radiographic apex. His instrumentation process involved instrumenting into the periodontal ligament and beyond the confines of the apical construction. ${ }^{15}$ Despite Schilder's rationale for extending the RCT beyond the apical constriction, the majority of authors have agreed that the best anatomical location to end instrumentation and obturation is at the apical constriction. ${ }^{4}$

In Ricucci and Langeland's histopathological analysis of apical pulp tissue, they found that instrumentation and obturation to the AC, provided the best histological prognosis for root canal therapy (RCT). ${ }^{3}$ Over-instrumentation and overextension of obturation materials has been associated with a decrease in the overall success rate and a delay in periapical healing. ${ }^{16,3}$ However, WL short of the AC may lead to inadequate debridement of the RCS. Sjogren found that teeth with under extended obturation by greater than two millimeters had lower success rates than teeth with over extended fillings, which in turn, had lower success than teeth with root fills at 0 to $2 \mathrm{~mm}$ from radiographic apex. ${ }^{17}$

Current methodology for locating the apical constriction include radiographic examination and the use of electronic apex locators. Neither method is devoid of error, however, several authors have found EALs to be more accurate than radiographic methods. Microscopic studies have shown that the AC is located $0.5 \mathrm{~mm}-0.75 \mathrm{~mm}$ coronal to the MF, which in turn is located about $0.5 \mathrm{~mm}$ coronal to the anatomical apex. Consequently, radiographic examination for working length is generally based off the estimate of $0.5-1.0 \mathrm{~mm}$ short of the radiographic apex. ${ }^{20,9}$ The major foramen has been shown to be some distance from the radiographic apex, even located up to $3.5 \mathrm{~mm}$ away. ${ }^{21}$ In a clinical situation as this, radiographic determination can lead to overextension, depending on the angulation of the film and the location of the major 
foramen. However, an estimation of the apical constriction being $1.0 \mathrm{~mm}$ short of the radiographic apex has also been shown to result in under-instrumentation. ${ }^{22}$ Thus a WL determined only through radiographic means may lead to instrumentation and obturation beyond the AC, which may increase postoperative pain and delay healing or lead to incomplete cleaning and shaping of the RCS with a short WL. ${ }^{23}$

Vieyra compared two EALs to radiology and found that both the Root XZ and Elements Diagnostic apex locators measurements of the AC were within $0.5 \mathrm{~mm}$ of the AC $100 \%$ of the time; whereas, radiographic methods were within this range only $15 \%$ of the time. ${ }^{24}$ Baumgartner also found that when a file was positioned either short or at the radiographic apex it was past the apical constriction $68 \%$ of the time. ${ }^{25}$ Collectively, authors have found EALs to have an accuracy between $43.9 \%$ and $89.1 \%$ efficiency at locating the apical constriction as compared to radiographic means which have been found to have between $14.6 \%$ and $32.72 \%$ histologically. ${ }^{26}$ These discrepancies occur as radiographic means are subject to distortion and magnification error. Voorde and Bjorndahl found there to be a 5.4\% magnification error when using a paralleling technique. ${ }^{18}$ Williams et al mentioned that two trends should be considered when radiographic working length is determined. When a file is long radiographically, it is actually longer than it appears by an average of $1.2 \mathrm{~mm}$. Whereas, when a file is short radiographically, it is closer to the MF than it appears by an average of $0.46 \mathrm{~mm}$. This can occur as radiographic means of WL determination cannot give an indication of an apical constriction that is located well short of the anatomical apex. ${ }^{19}$ Radiographic determination is solely based on a visual estimation of a 2-D image of a 3-D object, which has great anatomical variations.

With the inherent limitations of radiographic determination of working length exclusively, many clinicians use electronic apex locators as their primary method of determining 
working length. Custer in 1918 first examined an electronic method for locating the apical foramen. ${ }^{27}$ Later in 1942, Suzuki examined the flow of direct electrical current through the oral mucosa and dentition in dogs. He found consistent values for electrical resistance when an instrument was placed within the RCS and an electrode on the dog's oral mucosa. ${ }^{28}$ Sunada advanced these principles further with his research in 1962. He found that the electrical resistance of the human mucous membrane and the periodontium was 6.0 kilo ohms, irrespective of differences in age and tooth type. He developed a device that used these electrical resistance measurements to calculate the length of the root canal, which marked the birth of modern EALs. $^{29}$

The basic design of apex locators is based on an electrical circuit that incorporates the human body. One electrode is attached to the lip with a lip clip and the other electrode is attached to the end of a stainless steel endodontic file placed inside the RCS. When the stainless steel file touches the periradicular tissues the resistance decreases, which is signaled differently according to the type of EAL employed and its specific indicator screen. ${ }^{30}$

The first generation apex locators were based on electrical resistance. This measures the opposition an electrical current experiences as it travels through a conductor. Some devices within this group were the Root Canal Meter, Endodontic Meter and Endodontic Meter S II (Onuki Medical Co., Tokyo, Japan), the Dentometer (Dahlin Electromedicine, Copenhagen, Denmark), and the Endo Radar (Electtronica Liarre, Imola, Italy). Discrepancy was found in their ability to determine WL as compared to radiographic means. Great variations were found, with many of their readings being well beyond or short of the apical constriction. ${ }^{31}$ 
The second generation apex locators began to use single frequency impedance measurements as opposed to resistance to measure location within the RCS. Impedance measures the resistance of an alternating current. This reflected a change from using direct currents with the first generation to the use of alternating currents, where the flow of the electrical charge can be reversed. This enabled clinical canal conditions, such as moisture from sodium hypochlorite, to not affect the EAL reading, which was a frequent complaint with the first generation of apex locators. ${ }^{30}$ Inoue developed the Sono-Explorer (Hayashi Dental Supply, Tokyo, Japan) in 1971, which marked the first EAL that instituted a change from direct current to alternating current. The device indicated when the apex was reached by a beeping sound, which was uncharacteristic of the time. ${ }^{32}$ The model Sono-Explorer Mk III switched from the beeping sound to using a meter to designate the distance to the apex. ${ }^{33}$

The Endocater further made readings in wet canals more feasible, by having a sheath over the probe that entered the RCS. This would protect the probe somewhat from conductive fluids within the canal. ${ }^{34}$ However, the sheath was not able to enter smaller canals due to its large size, and was difficult to autoclave. ${ }^{35}$ Others also tried to improve EALs ability to determine WL within the clinical environment of conductive fluids. Ushiyama introduced a voltage gradient method that "measured the current density evoked in a limited area of the canal, the maximum potential of which is obtained when the electrode meets a constriction". This method could work in the presence of conductive fluids but also had an electrode that could not fit in narrow canals and was limited by variations in the location of a constriction. ${ }^{30}$

Third generation apex locators use impedance of multiple frequencies to determine the distance from the end of the canal. These devices are able to process the mathematical calculations required when using multiple frequencies to give accurate readings. The Root ZX 
(J. Morita, Tokyo, Japan) introduced by Kobayashi was the first self-calibrating EAL. ${ }^{37}$ The Root ZX works by the ratio method which works "on the principle that two electric currents with different sine wave frequencies will have measurable impedances that can be measured and compared as a ratio regardless of the type of electrolyte in the canal." The ratio of the impedances reduces rapidly as the apical constriction is reached. Kobayashi and Suda showed that the ratio of different frequencies have definitive values, and that the ratio rate of change did not change with different electrolytes in the canal. The change in ratio at the apical constriction is the basis for the operation of the Root ZX and its reported accuracy". ${ }^{38}$ The Root ZX has become the standard by which other apex locators where compared against. Other third generation EALs used where the Apex Finder AFA (EIE Analytic Endodontics), the Neosono Ultima EZ (Satelec Inc. Mount Laurel, NJ), the Justwo of Justy II (Yoshida Co., Tokyo, Japan), the Mark V Plus (Moyco/Union Broach, Bethpage, NY), and the Endy 5000 (Loser, Leverkusen, Germany). The Root ZX however, continued to have the majority of the market share. These apex locators are reported to continue to have inaccuracies with fluids in the canal. ${ }^{30}$

Fourth generation apex locators, take the resistance measurements and compares them with a database of the electrical characteristics of the canal to determine the distance to the apex of the root canal. These devices are reported to perform better by several percent in the presence of blood and exudate. ${ }^{39}$ Efforts have been continuously directed at improving apex locators, with fifth and sixth generation EALs on the market today. ${ }^{40}$

The Root ZX II was invented in 1992 and according to manufacturer claims was the first unit with the ability to work in wet canals, not affected by electrolytic fluids or the presence of blood. ${ }^{41}$ All five EALs claim to work in a variety of RCS environments. ${ }^{41,42,43,44,45}$ The Apex ID works through dual frequencies impedance. ${ }^{42}$ The Endo-EZE FIND uses "multi-frequency- 
dependent impedance method and proprietary algorithms to determine the position of the apical foramen."43 The Foramatron Apex Locator uses "high and low frequency bands to accurately pinpoint the apical constriction". ${ }^{44}$ The ProMARK EAL works through a multi-frequency impedance method and has been shown to be accurate with a variety of irrigation solutions. ${ }^{45}$ 


\section{Chapter 3}

\section{Material and Methods}

\section{Teeth Selection}

One hundred single rooted extracted teeth were evaluated under magnification (12.8x Global Surgical Corporation, St. Louis, MO) for evidence of defects that may affect the accuracy of the measurements of the EALS. Only roots that exhibited completely formed apices, no signs of resorption, and were patent with a number $08 \mathrm{~K}$-file (Lexicon) were included in the study. No preference was made regarding tooth type, length, or degree of root curvature.

\section{Tooth Preparation}

The crowns were sectioned at mid-level with a diamond bur to produce a flat working surface for the rubber stopper when determining working length. A \#3 Gates-Glidden bur was used to coronally flare the root canal system. Teeth were irrigated with $2.5 \%$ sodium hypochlorite.
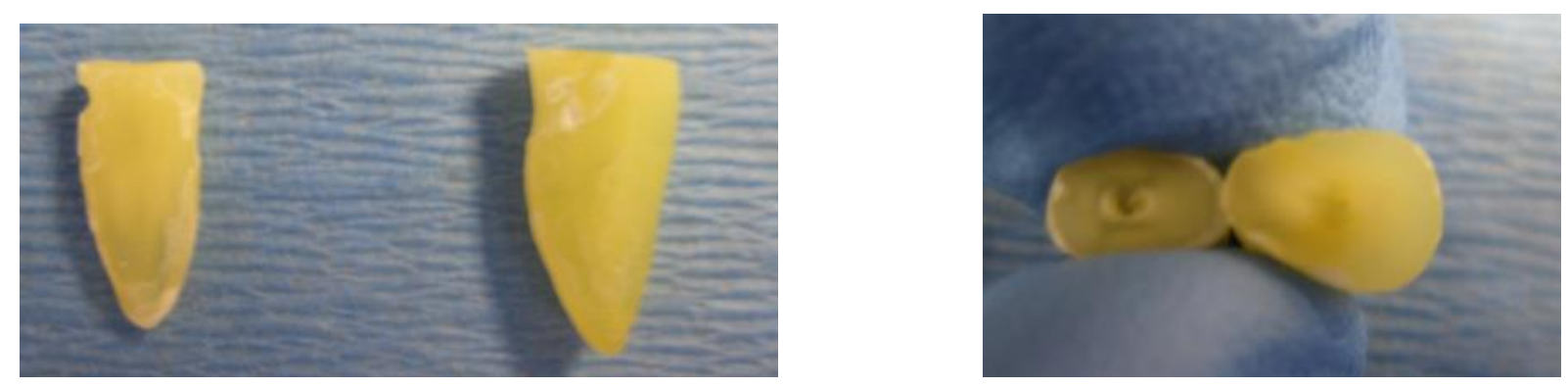

Figure 2. Coronal sectioning of teeth 


\section{Part 1: Accuracy in Determining the MF}

\section{Measurements}

To determine the control length of fifty of the canals, a \#15 K-file was introduced into the canal until it was just visible at the major apical foramen under the microscope $(12.8 \mathrm{x}$ magnification, Global Surgical Corporation, St. Louis, MO). The rubber stopper was then stabilized and the file was withdrawn. A calibrated digital caliper was used to measure the length from the file tip to the stopper to the nearest hundredth of millimeter $(0.01 \mathrm{~mm})$ and 0.5 mm was subtracted from this measurement as described by Ebrahim. ${ }^{47}$ This was determined to be the control length, or distance from the most incisive point to the major foramen.

To determine the physiological length for each specimen by EAL, the same fifty canals were evaluated by each of the five EAL. The teeth were embedded in an alginate model in groups of ten. A \#15 k-file was placed within the canal and advanced in the canal until each EAL indicated the file had reached the apical foramen. For the Root ZX (J Morita Co, Tokyo, Japan) this is indicated by "APEX" on the indicator screen. For the ProMark (Dentsply, Johnson City, TN) this is indicated by the first red bar. For the Endo-Eze Find (Ultradent Products, Inc, South Jordan, UT) this is indicated by " 0.0 " on the indicator screen. For the Apex ID (Kerr Endodontics, Orange, CA) this is indicated by a red bar and "APEX". For the Formatron Apex Locator (Parkell, Inc., Edgewood, NY) this is indicated by a "0.0" red light. The rubber stopper was then stabilized and the file was withdrawn, with the length measured to the nearest hundredth of millimeter $(0.01 \mathrm{~mm})$ with a digital caliper. This measurement indicated the PL or distance to the major foramen as determined by EAL. This distance was then subtracted from the control length and recorded. 


\section{Part 2: Reliability of the Indication of the Apical Constriction}

The remaining fifty teeth were divided into five groups of ten per EAL. They were then embedded by group into alginate. A size $15 \mathrm{k}$-file was advanced until the EAL indicated it was past the MF, then the file was retreated until the EAL indicated that the file was at the apical constriction. For the Root ZX (J Morita Co, Tokyo, Japan) this is indicated by " 0.5 " on the indicator screen. For the ProMark (Dentsply, Johnson City, TN) this is indicated by the last yellow bar. For the Endo-Eze Find (Ultradent Products, Inc., South Jordan, UT) this is indicated by " 0.5 " on the indicator screen. For the Apex ID (Kerr Endodontics, Orange, CA) this is indicated by a green bar. For the Formatron Apex Locator (Parkell, Inc., Edgewood, NY) this is indicated by a " 0.5 " yellow light.

The file was then cemented in place (Fuji Cem 2, GC Corp, Alsip, IL) and the tooth removed from the alginate. The apical $5 \mathrm{~mm}$ was then cautiously sectioned with a diamond bur and Sof-Lex discs (3M ESPE Dental Products, St Paul, MN) under magnification (12.8x), until the file was exposed. Digital images were acquired under magnification and analyzed by Image analysis software (Image $\mathrm{J}, 1.41 ; \mathrm{NIH}$ ). The distance from the file tip to the major foramen was measured to the nearest hundredth mm. 


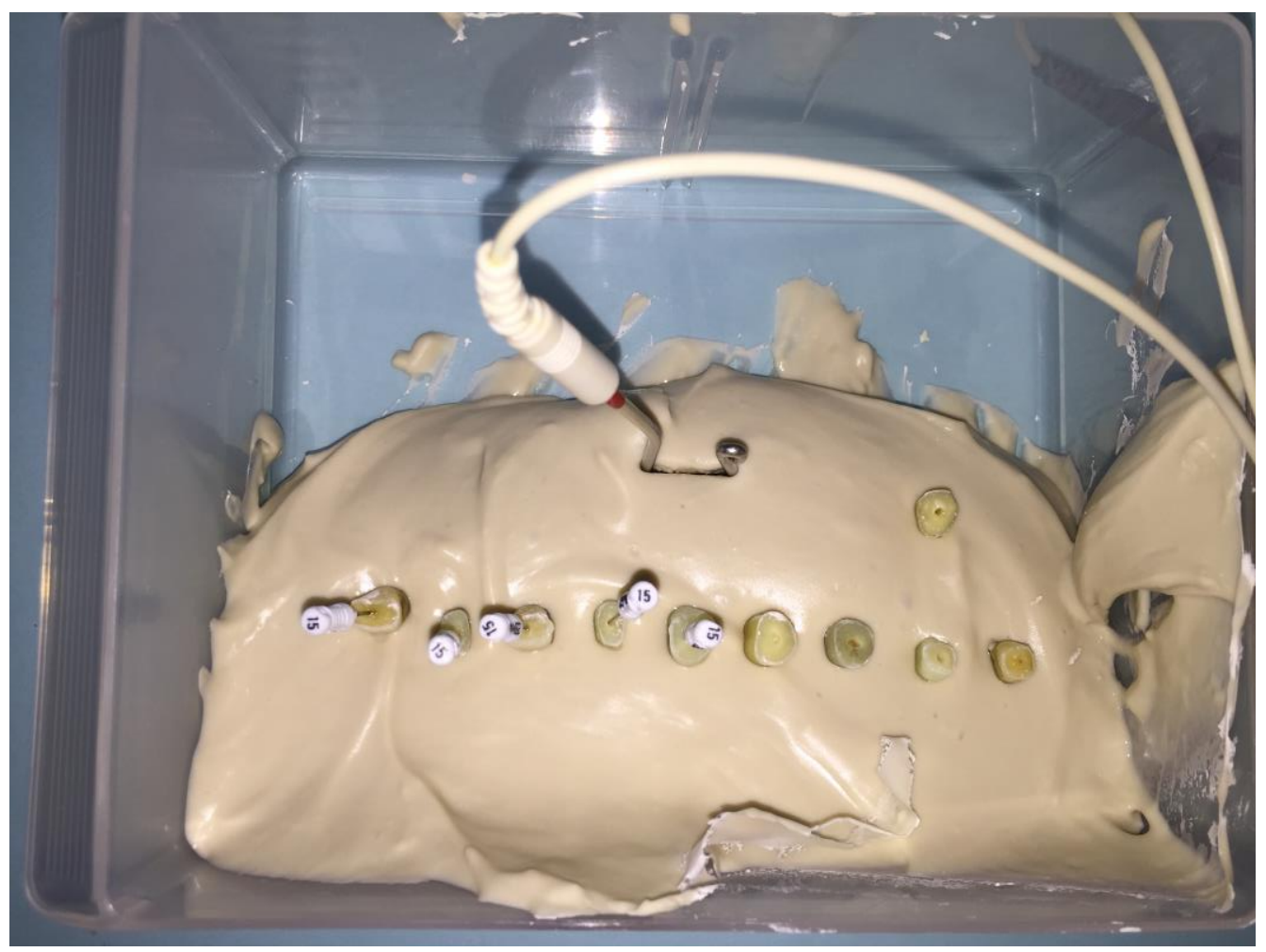

Figure 3. Groups of 10 teeth embedded in alginate

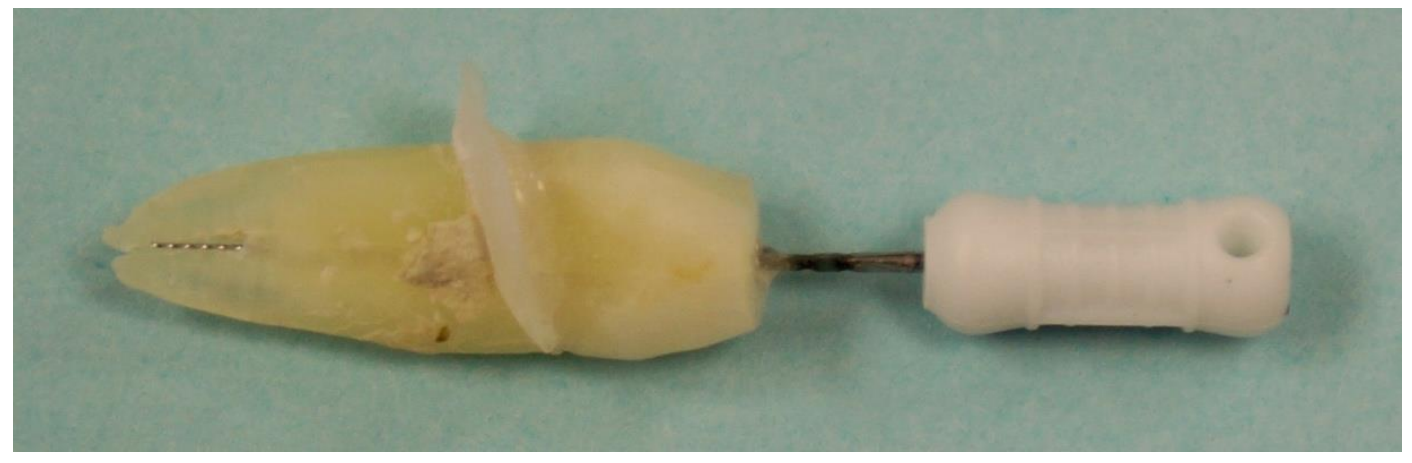

Figure 4. File cemented in place with last $5 \mathrm{~mm}$ sectioned with file exposed 


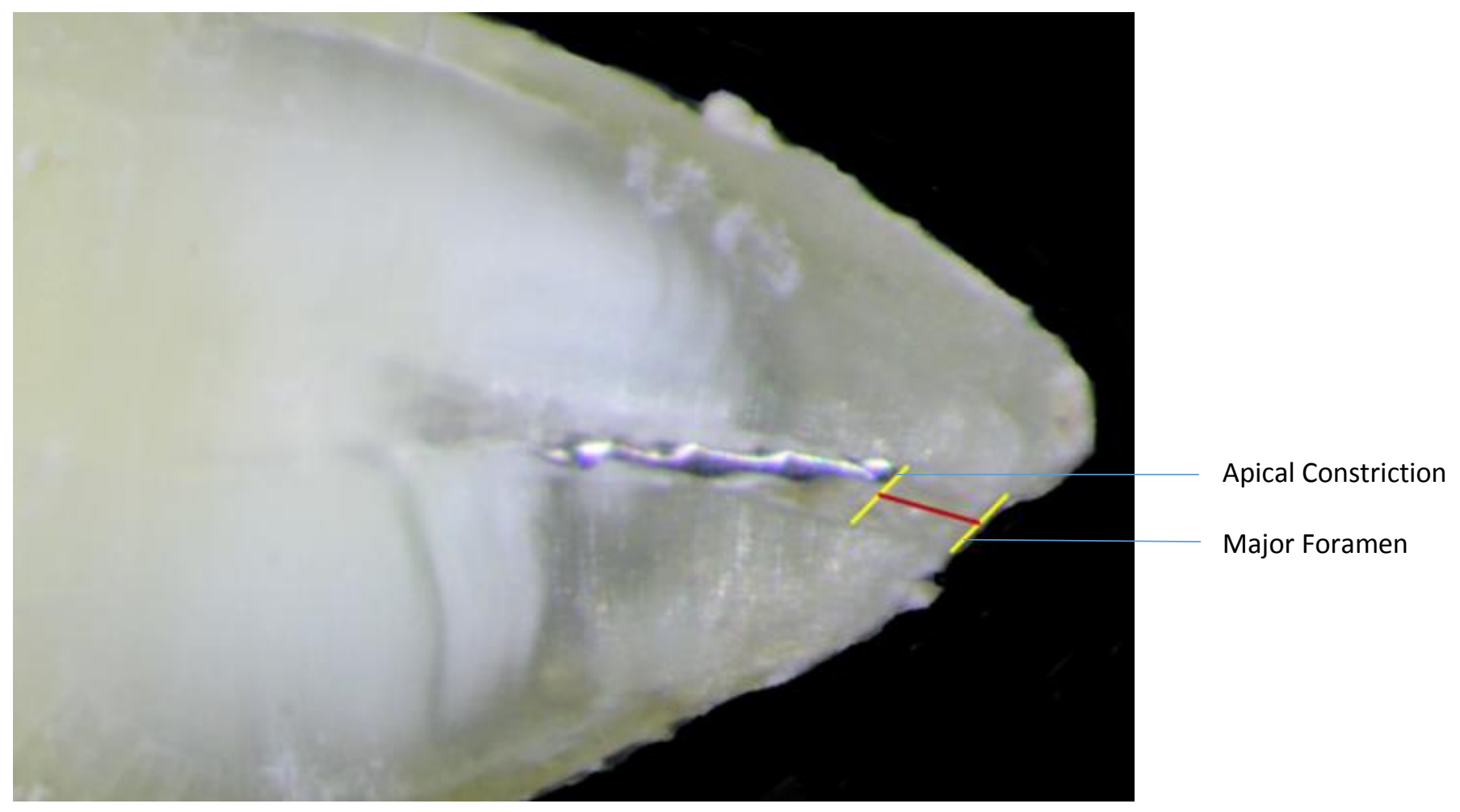

Figure 5. Measurement from file tip at designated "AC" to MF 


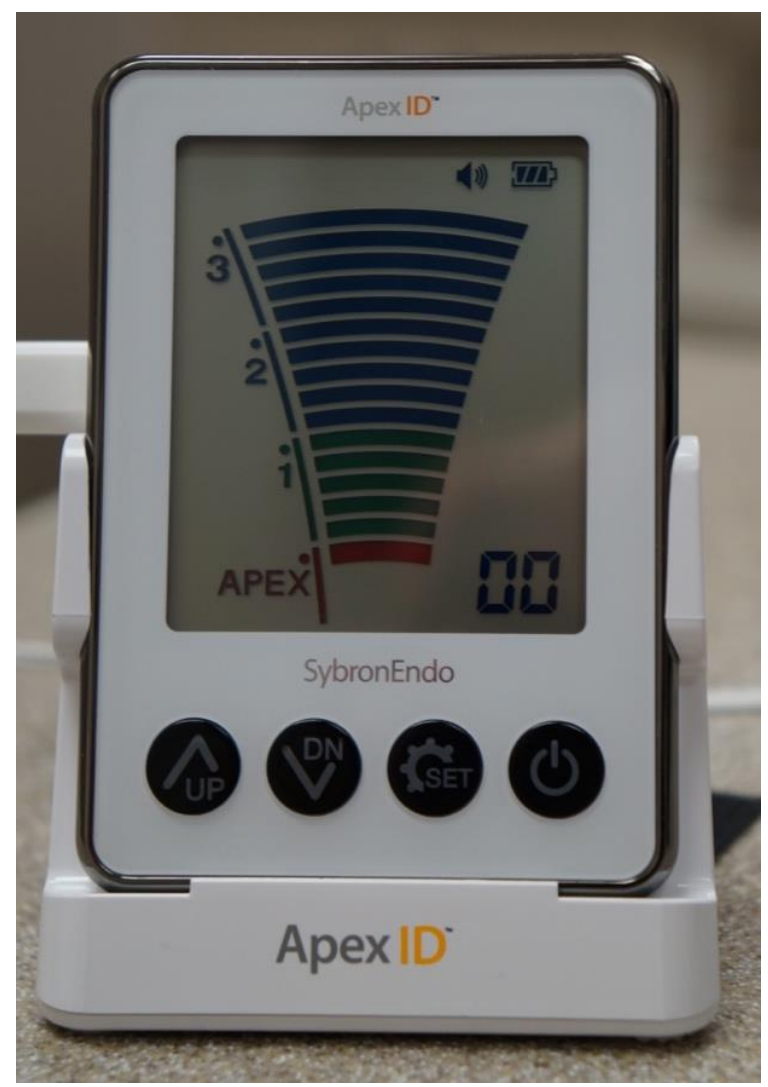

Figure 6. Apex ID indicator screen indicating that the MF has been reached

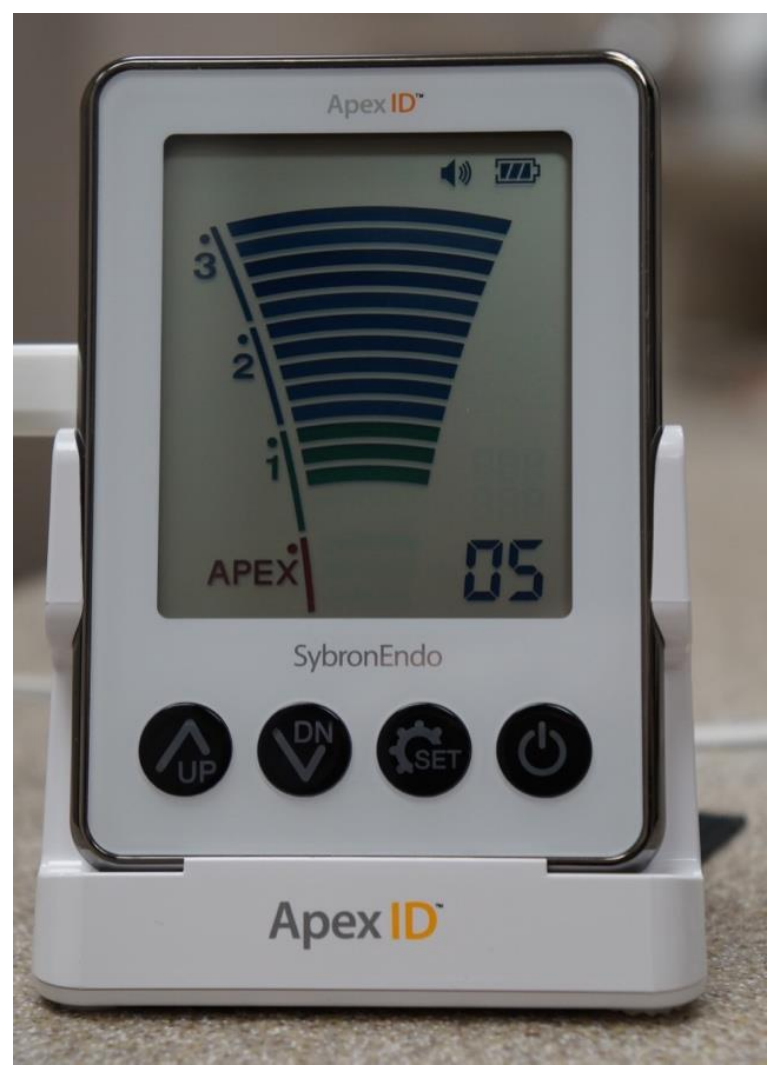

Figure 7. Apex ID indicator screen indicating that the $\mathrm{AC}$ has been reached 


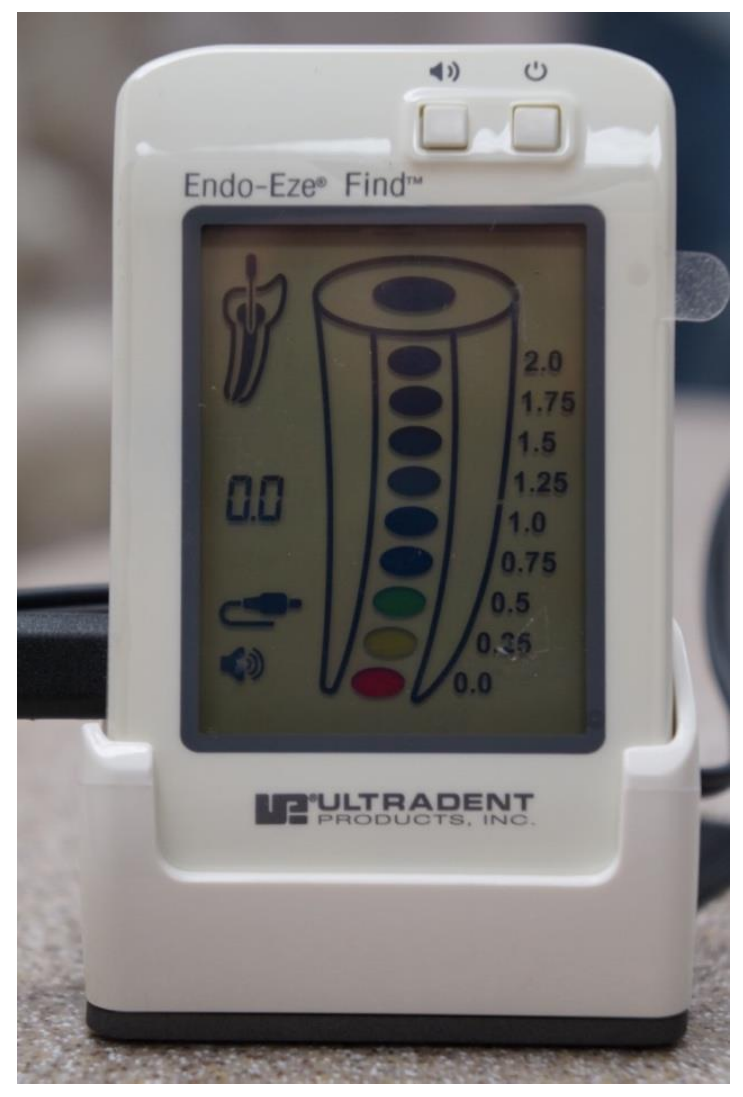

Figure 8. Endo-Eze Find indicator screen indicating that the MF has been reached

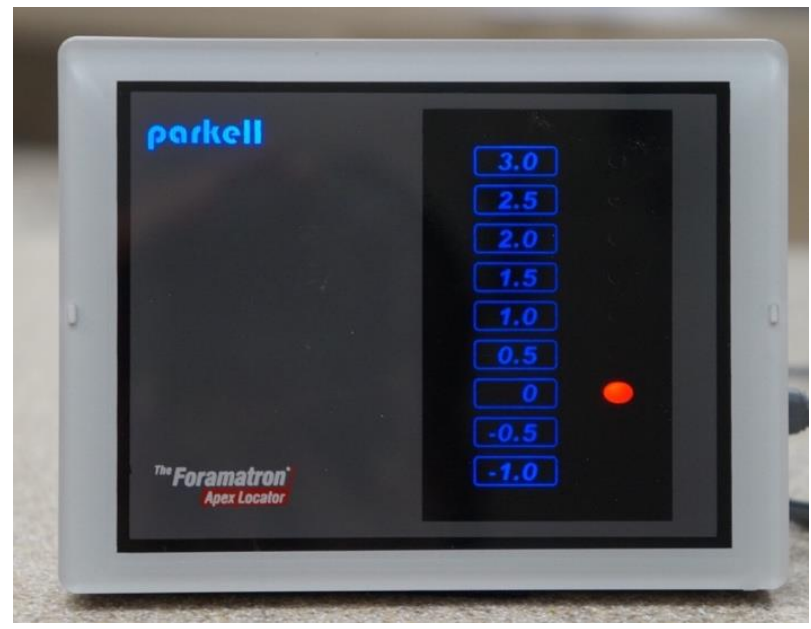

Figure 10. Foramatron indicator screen indicating that the MF has been reached

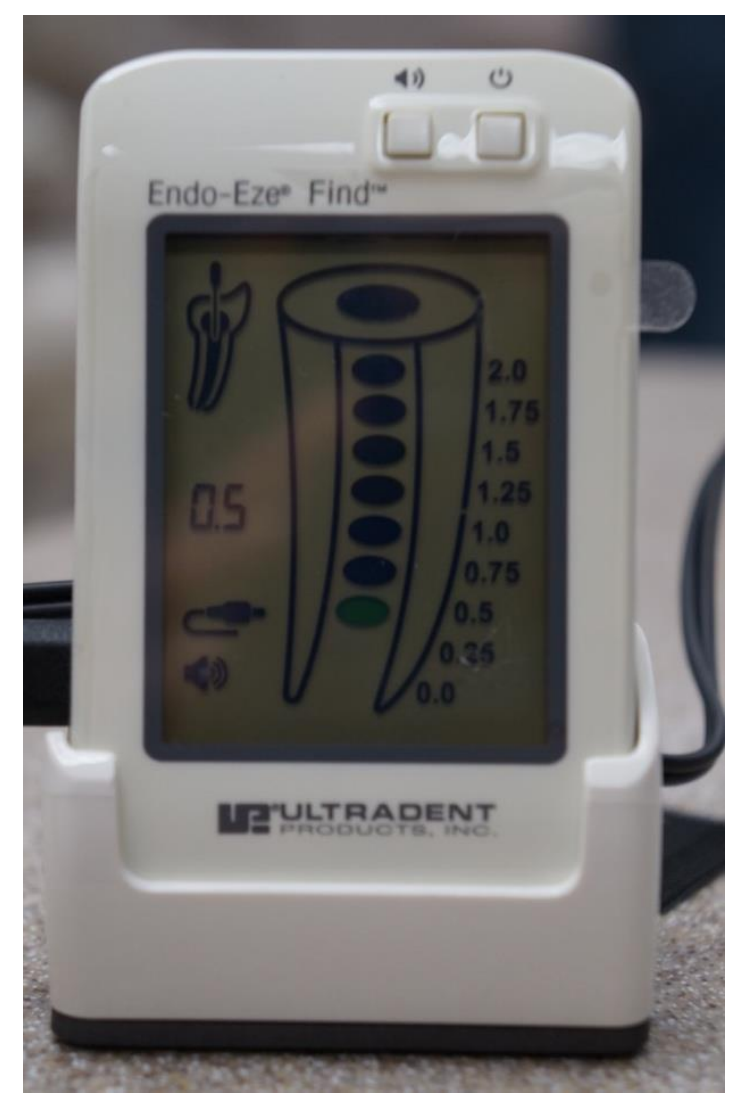

Figure 9. Endo-Eze Find indicator screen indicating that the $\mathrm{AC}$ has been reached

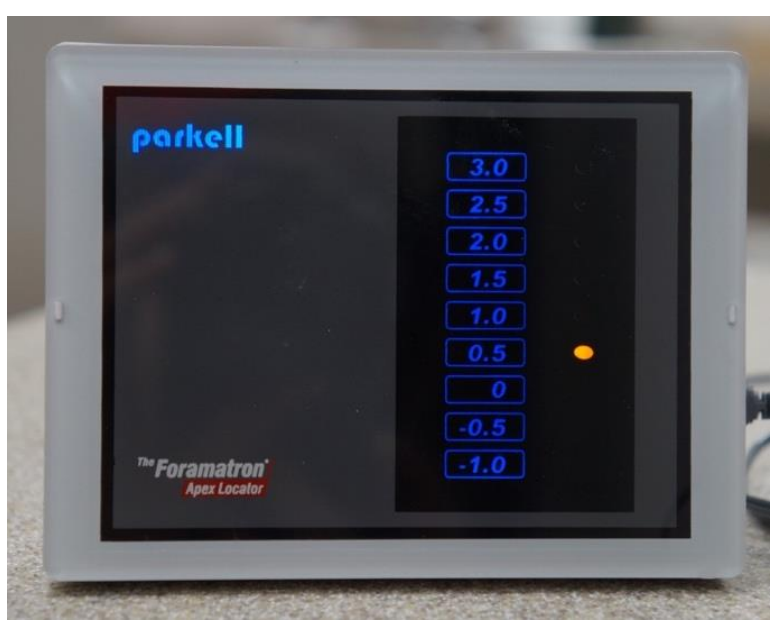

Figure 11. Foramatron indicator screen indicating that the $\mathrm{AC}$ has been reached 


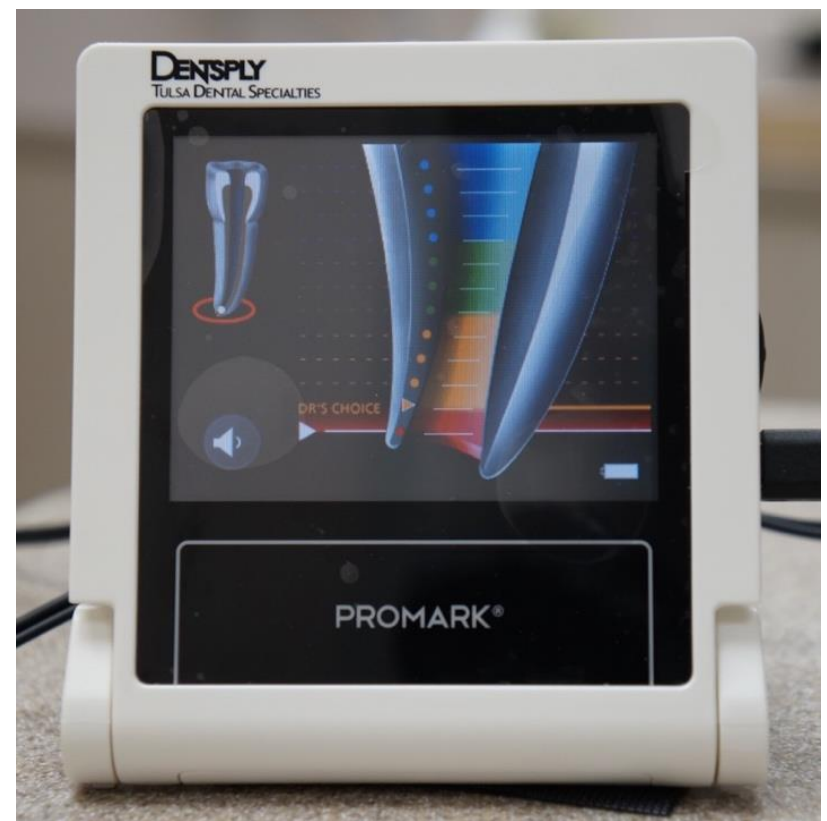

Figure 12. ProMARK indicator screen indicating that the MF has been reached

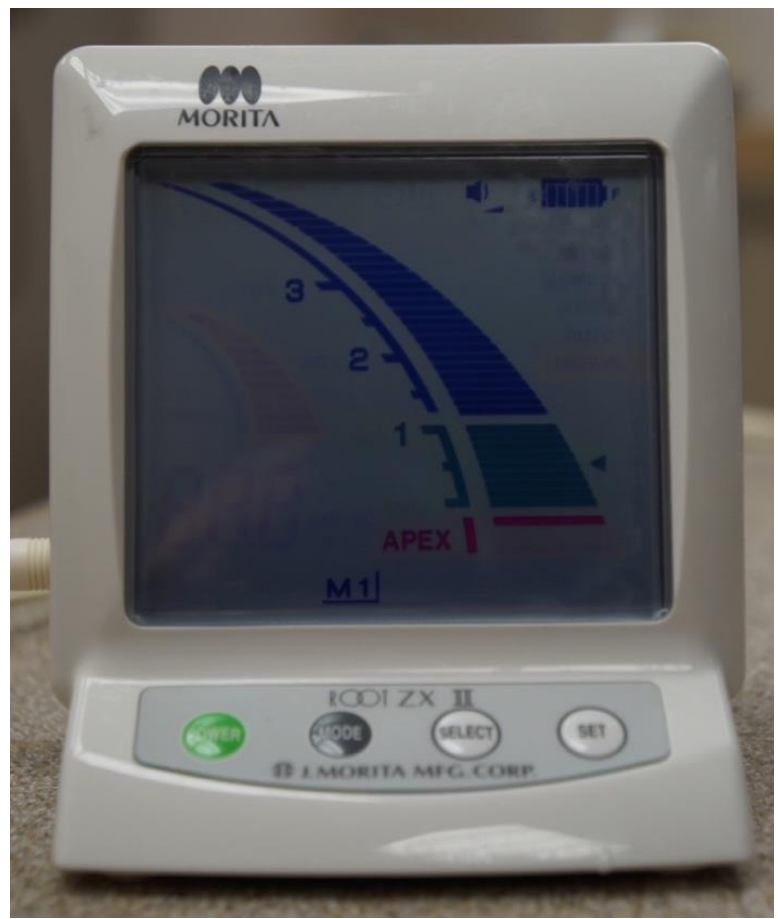

Figure 14. Root ZX II indicator screen indicating that the MF has been reached

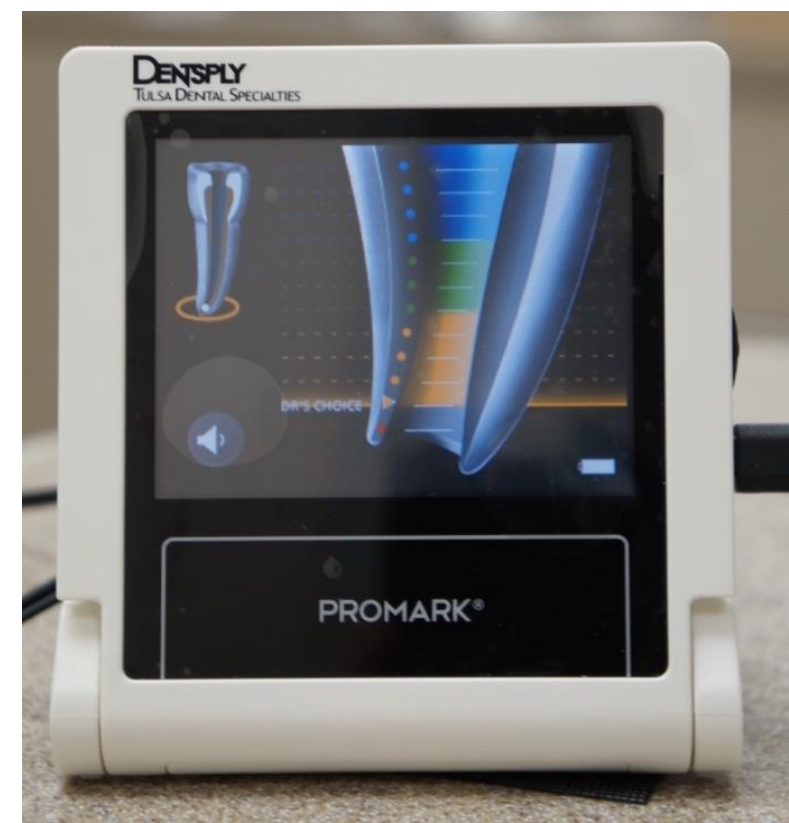

Figure 13. ProMARK indicator screen indicating that the $\mathrm{AC}$ has been reached

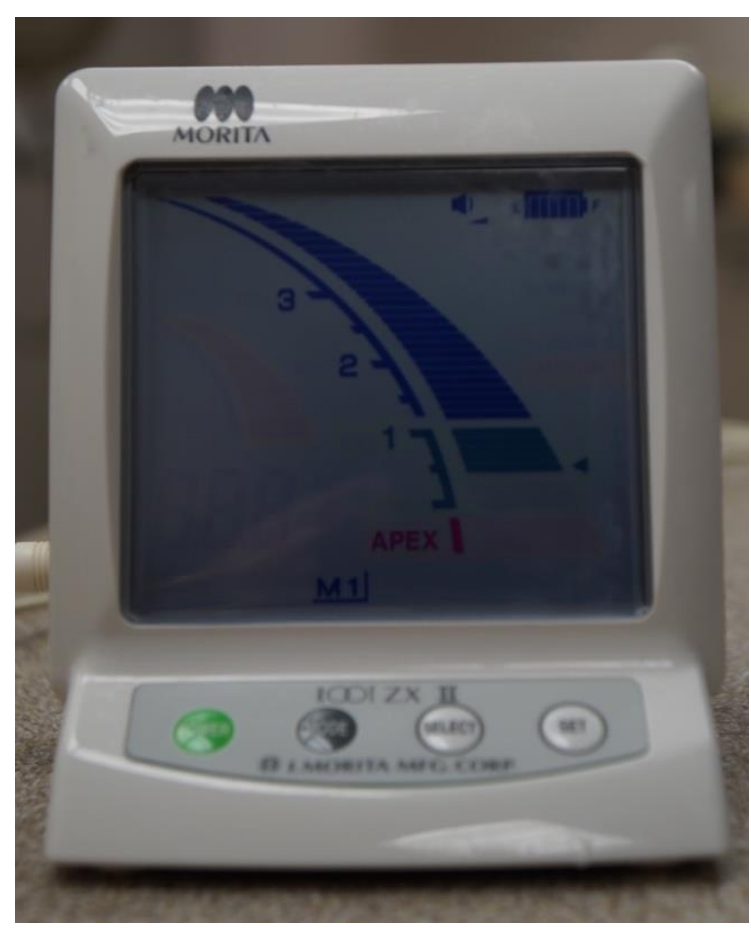

Figure 15. Root ZX II indicator screen indicating that the $\mathrm{AC}$ has been reached 


\section{Statistical Analysis}

Two sets of data were analyzed. The first set of data from fifty teeth was calculated by subtracting the millimeter distance of the PL as determined by EAL from the control length. A repeated-measures ANOVA analyzed the distance from the "APEX" indicator to the MF due to the repeated nature of the data. Tukey's Standardized Range test was employed to examine post hoc device difference. The second set of data from fifty additional teeth, was the measurement in millimeters of the file tip at the apical constriction to the major foramen, examined per EAL group. A non-parametric Kruskal-Wallis test was selected in the second analysis due to sample size and distributional concerns. Samples were assessed for distributional, size, and spread attributes, and statistical procedures were chosen. All statistical procedures were performed in SAS 9.3 (SAS Inc., Cary, NC). 


\section{Chapter 4}

\section{Results}

The data showed there was a statistically significant difference in the EALs ability to determine the major foramen, whereas, there was no statistically significant difference in the five EALs ability to reliably locate an apical constriction.

Fifty single-canaled anterior teeth were used to compare the Apex ID, Endo-EZE FIND, the Foramatron, ProMARK, and the Root ZX II ability to locate the MF. A P- value of $<0.0001$ was found when all fifty canals and five EALs were compared. There was a statistically significant difference between the five EAL mean differences in MF determination. The Apex ID and Root ZX II were more accurate than the Endo-Eze FIND, Formatron, and ProMARK in determining in the MF. Table 1 shows the mean, minimum, maximum, and range of the difference in mm between the control length and the PL as determined by the EAL and the indicator marks on the display screen for the MF. The mean difference between EAL PL measurements and microscopic measurements, or actual length for the five EAL (Apex ID, Endo-Eze FIND, Foramatron, ProMARK, and Root ZX II) was $0.136 \mathrm{~mm}$. The mean length for Apex ID measurement averaged $0.03 \mathrm{~mm}$ short of the microscopic PL. The mean length for the Root ZX II measurement averaged $0.05 \mathrm{~mm}$ short of the microscopic PL. The Endo-Eze FIND, Foramatron and ProMARK averaged 0.19, 0.22, and 0.19 short respectively. Figure 16 illustrates these distributions. Figure 16 visually shows the distribution of the PL as indicated per EAL. 


\begin{tabular}{|l|c|c|c|c|l|}
\hline$(\mathrm{n}=50)$ & Mean (mm) & SD (mm) & Min. (mm) & Max. (mm) & $\begin{array}{c}\text { Range } \\
(\mathbf{m m})\end{array}$ \\
\hline Apex ID & -0.029 & 0.287 & 0 & 0.73 & $\begin{array}{l}0.73 \text { to } \\
-0.67\end{array}$ \\
\hline Endo-Eze FIND & -0.201 & 0.321 & 0 & -0.73 & $\begin{array}{l}0.68 \text { to } \\
-0.84\end{array}$ \\
\hline Foramatron & -0.137 & 0.673 & -0.01 & 3.88 & $\begin{array}{l}3.88 \text { to } \\
-0.81\end{array}$ \\
\hline ProMARK & -0.202 & 0.335 & 0.01 & -0.86 & $\begin{array}{l}0.42 \text { to } \\
-0.86\end{array}$ \\
\hline Root ZX II & -0.056 & 0.318 & -0.03 & 0.63 & $\begin{array}{l}0.63 \text { to } \\
-0.65\end{array}$ \\
\hline
\end{tabular}

Table 1. Difference (mm) per EAL between the PL and the control length. Minimum measurement indicates the least amount of distance $(\mathrm{mm})$ from the MF measured. Maximum measurement indicates the greatest amount of distance $(\mathrm{mm})$ from the MF measured. Negative numbers are coronal to the MF, or within the RCS. Positive numbers extend past the MF. 

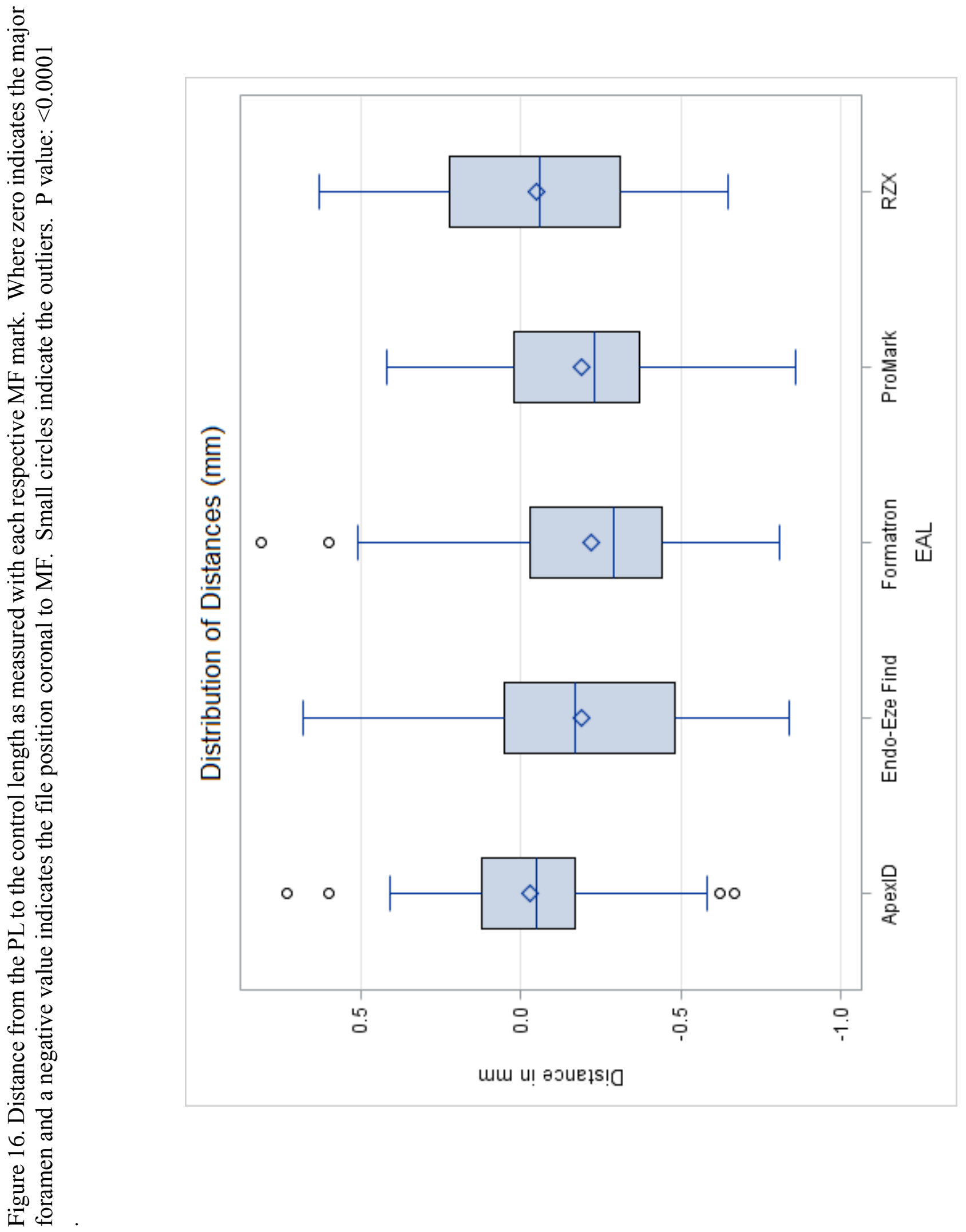
Table 2 shows the mean, minimum, maximum and range of the distance in $\mathrm{mm}$ from the file tip at the designated AC point by EAL and the MF. The average distance for all five EAL from the file tip to the AC designation was $0.49 \mathrm{~mm}$ coronal to the MF. The mean distances (mm) from the file tip to the designated AC point to the MF per EAL (Apex ID, Endo-Eze FIND, Foramatron, ProMARK, and Root ZX II) were $0.64,0.56,0.48,0.12$, and 0.63 coronal to the MF respectively. There was no statistically significant difference with a Kruskal-Wallis analysis. Figure 17 illustrates these differences.

\begin{tabular}{|l|c|c|c|c|c|}
\hline (n=10) & Mean (mm) & SD (mm) & Min. (mm) & Max (mm) & $\begin{array}{c}\text { Range } \\
(\mathbf{m m})\end{array}$ \\
\hline Apex ID & -0.24 & 1.311 & 0 & -0.36 & 0 to -0.36 \\
\hline Endo-Eze FIND & -0.56 & 0.923 & 0 & -2.81 & $\begin{array}{c}0.87 \text { to }- \\
2.81\end{array}$ \\
\hline Foramatron & -0.48 & 0.413 & 0 & -1.12 & $\begin{array}{c}0.16 \text { to }- \\
1.12\end{array}$ \\
\hline ProMARK & -0.12 & 0.414 & 0 & -0.92 & $\begin{array}{c}0.67 \text { to }- \\
0.92\end{array}$ \\
\hline RZX II & -0.63 & 0.623 & -0.48 & -2.01 & $\begin{array}{c}0.48 \text { to }- \\
2.01\end{array}$ \\
\hline
\end{tabular}

Table 2. Distance ( $\mathrm{mm}$ ) from the file tip to the MF. Minimum measurement indicates the least amount of distance ( $\mathrm{mm}$ ) from the MF seen. Maximum measurement indicates the greatest amount of distance $(\mathrm{mm})$ from the MF seen. Negative numbers are coronal to the MF, or within the RCS. Positive numbers extend past the MF. 


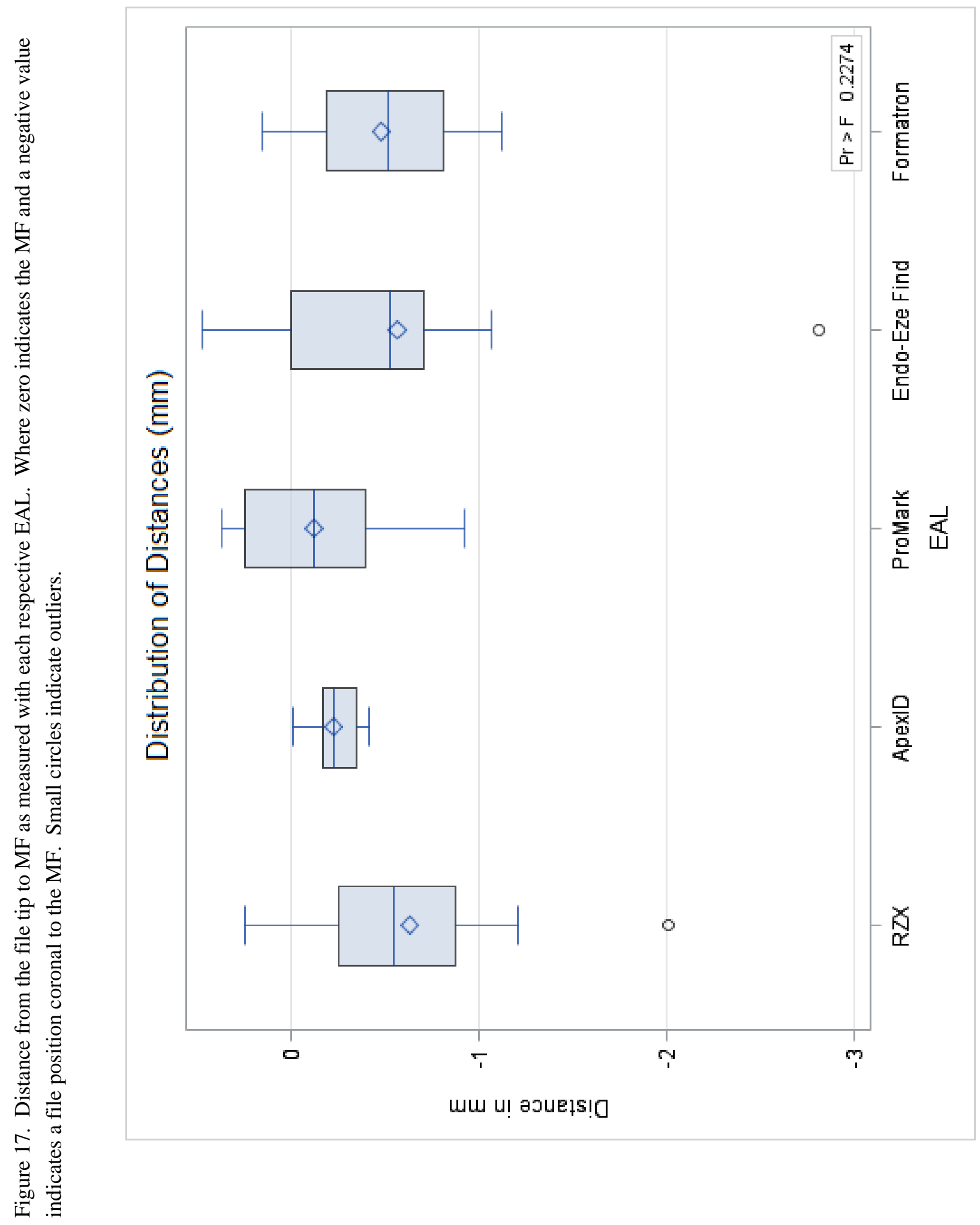


Table 3 illustrates the accuracy of each EAL at varying guidelines of accuracy. The standards assessed were from the defined level of $0.0 \mathrm{~mm}$ long to $0.5 \mathrm{~mm}$ short, $0.0 \mathrm{~mm}$ long to $1.0 \mathrm{~mm}$ short, $0.5 \mathrm{~mm}$ long to $0.5 \mathrm{~mm}$ short, $0.5 \mathrm{~mm}$ long to $1.0 \mathrm{~mm}$ short. The Apex ID had $100 \%$ of its measurements fall into the strictest category.

\begin{tabular}{|c|c|c|c|c|}
\hline$(\mathrm{n}=10)$ & $\begin{array}{l}0 \mathrm{~mm} \text { to } \\
-0.5 \mathrm{~mm}\end{array}$ & $\begin{array}{l}0 \mathrm{~mm} \text { to } \\
-1.0 \mathrm{~mm} \\
\end{array}$ & $\begin{array}{c}0.5 \mathrm{~mm} \text { to } \\
-0.5 \mathrm{~mm}\end{array}$ & $\begin{array}{c}0.5 \mathrm{~mm} \text { to } \\
-1.0 \mathrm{~mm}\end{array}$ \\
\hline Apex ID & $100 \%$ & & & \\
\hline $\begin{array}{l}\text { Endo-Eze } \\
\text { FIND }\end{array}$ & $20 \%$ & $60 \%$ & $40 \%$ & $80 \%$ \\
\hline Foramatron & $40 \%$ & $80 \%$ & $50 \%$ & $90 \%$ \\
\hline ProMARK & $50 \%$ & $60 \%$ & $90 \%$ & $100 \%$ \\
\hline RZX II & $40 \%$ & $70 \%$ & $50 \%$ & $70 \%$ \\
\hline
\end{tabular}

Table 3. Percentage by EAL at different standards of accuracy, where zero indicates the file tip at the MF, a negative number indicates the file tip coronal to the MF, a positive number indicates the file tip extended past the MF.

\section{Discussion}

The aim of this study was to assess the ability of five EAL accuracy in locating the MF and then their reliability in indicating an apical constriction. The EALs evaluated were the Apex ID, Endo-Eze FIND, Foramatron, ProMARK, and Root ZX II. The Root ZX II has historically been the gold standard to which EALs are compared too. A statistically significant difference 
was found in the Apex ID and Root ZX II abilities to locate the MF. No statistically significant difference was found in the 5 EALs reliability of locating an apical constriction.

The canals were pre-flared with Gates Glidden, as it has been shown to increase the accuracy of EAL. ${ }^{54,51}$ Several different mediums have been used for in vitro experiments, such as alginate, saline, gelatin, and commercially sold products. This study used alginate as its consistency resists forces applied by the movement of the file and intrusion of material into the MF and has been shown to be an accurate method of demonstrating the use of an EAL. ${ }^{52}$ In a study by Chen et al to determine ideal teaching models, alginate was shown to be more accurate than gelatin, and saline when compared to microscopic determination of WL. ${ }^{53}$

In this study, the Root ZX II and Apex ID were found to be more accurate than the EndoEze FIND, Foramatron, and ProMARK at locating the MF. The five EALs were evaluated by the mean difference in the control length minus the PL. Variables such as apical anatomy did not affect the outcome as each EAL was used on each of the fifty teeth. Each EAL range of measurements is listed in Table 1. The Apex ID, Endo-Eze FIND, ProMARK and Root ZX II all had similar ranges: 0.73 to $-0.67,0.68$ to $-0.84,0.42$ to -0.86 and 0.63 to -0.65 respectively, with the positive number indicating an overextension and the negative number being coronal to the MF. The Foramatron had a significant outlier of $3.8 \mathrm{~mm}$ long of the major foramen, had this measurement not been included it would have a range of $0.81 \mathrm{~mm}$ long of the MF to $0.86 \mathrm{~mm}$ short of the MF. The ProMARK was the only EAL to not have an extension greater than $0.5 \mathrm{~mm}$ long of the MF. All others had extensions beyond $0.5 \mathrm{~mm}$.

The apical constriction has been shown to be an advantageous point to terminate instrumentation and obturation. Infected pulp tissue or dentinal chips forced into the periapical 
tissues can result in delayed healing or a foreign body reaction. ${ }^{17,55,56}$ Kuttler, found the apical constriction to be on average $0.59 \mathrm{~mm}$ away from the MF. ${ }^{9}$ A clinically acceptable EAL should place the WL termination within the anatomical landmarks of the AC and MF. ${ }^{48}$ With the addition of greater taper nickel titanium rotary files to endodontist's armamentarium, it is even more prudential for instrumentation to remain within the root canal system. A rotary file with a tip size of $0.4 \mathrm{~mm}$ and a taper of .06 taken out $1 \mathrm{~mm}$ past the MF, could enlarge the AC to 0.46 mm or even 0.64 depending on the anatomical location of the AC.

Numerous studies have reported on the accuracy of EALs for determining the location of the apical constriction. These studies have variations in the reference point from which measurement accuracy is evaluated, with some using the AC and some using the MF. ${ }^{48}$ Previous studies have also shaved the apical portion of the tooth along its long axis and then measured the distance from the file tip to the apical constriction to evaluate the accuracy of the apical constriction indicator. ${ }^{49}$ However, in this study the major foramen was used as the reference point from which the file tip was measured, as it has been shown that the apical constriction is extremely difficult to locate in the longitudinal direction. ${ }^{50}$ The reliability of each EAL location of an apical constriction within an acceptable range was evaluated.

Some researchers have used $+/-1.0 \mathrm{~mm}$ as a clinically acceptable range for WL determination, while others use more stringent clinical guideline of $+/-0.5 \mathrm{~mm}$. Shabahang stated that an error tolerance of $+/-1.0 \mathrm{~mm}$ is clinically acceptable as not all root canals end in a traditional apical constriction and the wide variety of apical shapes. 5,57

In this study, when evaluating the ability of each EAL to indicate an $\mathrm{AC}$ within $0 \mathrm{~mm}$ long to $1.0 \mathrm{~mm}$ short of the apical foramen, the APEX ID had a success rate of $100 \%$. The Endo- 
Eze FIND, Foramatron, ProMARK, and RZX II had rates of $60 \%, 80 \%, 60 \%$ and $70 \%$ respectively within this range. When evaluating $0.5 \mathrm{~mm}$ long to $1.0 \mathrm{~mm}$ short of the MF, the Apex ID had $100 \%$ of readings fall within this range. The Endo-Eze FIND, Foramatron, ProMARK, and RZX II had $80 \%, 90 \%, 100 \%$, and $70 \%$ respectively fall within this range. It is of note that the Apex ID did not have any over extensions of the file tip outside of the RCS. However, there was no statistical significant difference between the mean distance between the file tip and MF.

In vitro studies have shown the Root ZX II, was found to be $90-95 \%$ accurate $(+/-0.5 \mathrm{~mm}$ or $+/-1.0 \mathrm{~mm}$ when locating the major foramen. ${ }^{48}$ This study found 50 to $70 \%$ which is lower than previous studies, but this study had a small sample size of 10 teeth. A recent study found the Apex ID to be $93 \%$ accurate $+/-0.5 \mathrm{~mm} .{ }^{58}$ This is in accordance with this study, which found the Apex ID to be $100 \%$ accurate within that range. The Foramatron was shown to be $100 \%$ accurate within $+/-0.5 \mathrm{~mm}$ in a study by Ebrahim. ${ }^{59}$ This varied greatly from our findings of $50 \%$ accuracy at that level. A literature search did not result in any previous studies evaluating the Endo-Eze FIND or ProMARK.

When purchasing dental equipment, clinicians want the most cost efficient and effective technology available. The devices in this study range from $\$ 615.00$ to $\$ 997.35$, with the most expensive being the ProMark and the least being the Foramatron. Table 4 shows the cost per device tested. 


\begin{tabular}{|l|l|l|c|}
\hline Device & Company & Mechanism & Cost \\
\hline Apex ID & Kerr Dental Co. & Multi-frequency impedance method & $\$ 817.55$ \\
\hline $\begin{array}{l}\text { Endo-Eze } \\
\text { Find }\end{array}$ & Ultradent Products Inc. & Multi-frequency dependent impedance & $\$ 899.95$ \\
\hline Foramatron & Parkell Inc. & High and low frequency bands & $\$ 615.00$ \\
\hline ProMARK & Dentsply & Multi-frequency impedance method & $\$ 997.35$ \\
\hline Root ZX II & J. Morita & Multi-frequency impedance method & $\$ 949.49$ \\
\hline
\end{tabular}

Table 4: Cost per device evaluated

Eradicating the bacteria within the root canal system, whilst maintaining the integrity of the root canal system is an important clinical step. Seltzer et al showed that the success rate of endodontic treatment was affected by both over extension and under extension. ${ }^{60}$ A clinician needs to be able to efficiently and accurately determine working length. Within the constraints of this study, the Apex ID overall outperformed the other EAL in accuracy, lack of overextensions, and is an economical choice. 


\section{Chapter 5}

\section{Conclusion}

The Apex ID and Root ZX II were more accurate in their location of the major foramen.

All five EALs performed within the same level of consistency in their estimation of an apical constriction. The Apex ID estimation of the apical constriction resulted in no overextensions of the file tip beyond the major foramen. 


\section{Works Cited}

1. Glossary of Endodontic Terms, $8^{\text {th }}$ ed. American Association of Endodontists, 2015.

2. Cohen S. Hargreaves K. Pathways of the Pulp. $10^{\text {th }}$ ed., St Louis: Mosby, 2011;355.

3. Ricucci D, Langeland K. Apical Limit of Root Canal Instrumentation and Obturation, Part 2. A Histological Study. Int Endod J. 1998;31:394-409.

4. Ricucci D. Apical limit of root canal instrumentation and obturation, part 1. literature review. Int Endod J. 1998;31(6):384-393.

5. Dummer PM, McGinn JH, Rees DG. The position and topography of the apical canal constriction and apical foramen. Int Endod J 1984;17:192-198.

6. Meder-Cowherd L, Williamson AE, Johnson W, Vasilescu D, Walton R, Qian F. Apical morphology of the palatal roots of maxillary molars by using micro-computed tomography. $J$ Endo. 2011;37:1162-1165.

7. Sunada I. New Method for measuring the length of the root canal. J Dent. 1962;41:375-387.

8. Ravanshad S, Adl A, Anvar J. Effect of working length measurement by electronic apex locator or radiography on the adequacy of final working length: a randomized clinical trial. $J$ Endod 2010;36(11):1753-1756.

9. Kuttler Y. Microscopic investigation of root apices. J Am Dent Assoc. 1955;50:554-562.

10. Marceliano-Alves M. Alves FR. Mendes D. et al. Micro-computed tomography analysis of the root canal morphology of palatal roots of maxillary first molars. J Endod 2016;42(2):280283.

11. ElAyouti A, Hulber M, Judenhofer M, et al. Apical constriction: location and dimensions in molars- a micro-computed tomography study. J Endod 2014;40:(8) 1095-1099.

12. Weine F. Endodontic Therapy. St Louis, MO. Mosby, 1982;183-196. 
13. Langeland K. Pulp histology and physiology. Pathways of the Pulp, St Louis: Mosby, 1976;203-290.

14. Lin L, Shovlin F, Skribner J, Langeland K. Pulp biopsies from the teeth associated with periapical radioluciences. $J$ Endod;10:436-448.

15. Schilder H.Canal debridement and disinfection. Pathways of the Pulp, $2^{\text {nd }}$ ed. St Louis, USA: C.V. Mosby, 1976;111.

16. Molven O, Halse A, Fristad I, MacDonald-Jankowski D. Periapical changes following rootcanal treatment observed 20-27 years postoperatively. Int Endod J. 2002;35:784-790.

17. Sjogren U. Factors affecting the long-term results of endodontic treatment. J Endod. 1990;16:(10):498-504.

18. Vande Voorde H, Bjorndahl A. Estimating endodontic "working length" with paralleling radiographs. Oral Surg Oral Med Oral Pathol Oral Radiol Endod. 1969;27:106-110.

19. Williams C, Joyce A, Roberts S. A comparison between in vivo radiographic working length determination and measurement after extraction. $J$ Endod. 2006;32(7):624-627.

20. Ingle J, Bakland L, Baumgartner J. Endodontics. 6th ed. Hamilton, Ontario: BC Decker; 2008.

21. Green D. Stereo binocular microscopic study of the root apices and surrounding areas of 100 mandibular molars. Oral Surg Oral Med Oral Pathol Oral Radiol Endod. 1955;8(12):12981304.

22. Pratten D, McDonald N. Comparison of radiographic and electronic working lengths. $J$ Endod 1996;22:173-176.

23. Bergenholtz G, Lekholm U, Milthon R, et al. Retreatment of endodontic fillings. Scan J Dent Res. 1979;87:(3)217:224. 
24. Vieyra J, Acosa J, Mondaca J. Comparison of working length determination with radiographis and two electronic apex locators. Int Endod J. 2010;43(1):16-20.

25. Baumgartner J. Accuracy of electronic apex locators. Den Abstracts. 2006;51(2): 101-102.

26. Martins J, Marques D, Mata A, Carames J. Clinical efficacy of electronic apex locators: systematic review. J Endod. 2014;40(6):759-777.

27. Custer C. Exact methods for locating the apical foramen. J of Nat Dent Assoc. 1918;5:815819.

28. Suzuki K. Experimental study on iontophoresis. Japanese J of Stomatology. 1942;16:411429.

29. Sunada I. New method for measuring the length of the root canal. J Dent Res 1962;41:375387.

30. Gordon M, Chandler N. Electronic apex locators: A review. Int Endod J. 2004;37:425-437.

31. Tidmarsh B, Sherson W, Stalker N. Establishing endodontic working length: a comparison of radiographic and electronic methods. New Zealand Dent J. 1985;81:93-96.

32. Inoue N. Dental ‘stethoscope’ measures root canal. Dental Survey. 1972;48:38-39.

33. Inoue N. Skinner D. A simple and accurate way to measure root canal length. J Endod. $1985 ; 11: 421-427$.

34. Hasegawa K, Iizuka H, Takei M, Goto N, Nihei M, Ohashi M. A new method and apparatus for measuring root canal length. Journal of the Nihon University School of Dentistry. 1986;28:117-128.

35. Fouad A, Krell K, McKendry D, Koorbusch G, Olson R. Clinical evaluation of five electronic root canal length measuring instruments. J Endod. 1990;16: 446-449. 
36. Ushiyama J. Nakamura M. Nakamura Y. A clinical evaluation of the voltage gradient method of measuring the root canal length. $J$ Endod 1988;14:283-287.

37. Kobayashi C. Okiji T. Kaqwashima N. Suda H. Sunada I. A basic study on the electronic root canal length measurement: Part 3. Newly designed electronic root canal length measuring device using division method. Japanese Journal of Conservative Dentistry. 1991;34:1442-1448.

38. Kobayashi C. Suda H. New electronic canal measuring device based on the ratio method. $J$ Endod. 1994;20:111-114.

39. Nekoofar M, Sadeghi K, Akha E, et al. The accuracy of the Neosono Ultima EZ apex locator using files of different alloys: an in vitro study. J of the Californian Dent Assoc. 2002;30:681-684.

40. Dimitrov S, Roshkev D. Sixth generation adaptive apex locator. J of IMAB. Annual Proceeding, Scientific Papers. 2009;2:75-78.

41. Root ZX. Instructional materials. J. Morita, USA Inc. Tustin, CA.

42. Apex ID. Instructional materials. Kerr Dental. Orange, CA.

43. Endo-EZE Find. Instructional materials. Ultradent Products Inc. South Jordan, UT.

44. Foramatron. Instructional materials. Parkell Inc. Edgewood, NY.

45. ProMARK. Instructional materials. Dentsply. York, PA.

46. Lucena C, Lopez JM, Martin A, et al. Accuracy of working length measurement: electronic apex locator versus cone-beam computed tomography. Int Endod J. 2014;47:246-256.

47. Ebrahim AK., Wadachi R., Suda H. An in vitro evaluation of the accuracy of Dentaport ZX apex locator in enlarged root canals. 2007;52:(3): 193-196 
48. Tsesis I, Blazer T, Ben-Izhack G, et al. The precision of electronic apex locators in working length determination: A systematic review and meta-analysis of the literature. $J$ Endod. 2015;41(11):1818-1823.

49. Hassanien E, Hashem A, Chalfin H. Histomorphometric study of the root apex of mandibular premolar teeth: and attempt to correlate working length measured with electronic and radiograph methods to various anatomic positions in the apical portion of the canal. $J$ Endod. 2008;34(4): 408-412.

50. Olson DG, Roberts S, Joyce A, Collins D, McPherson J. Unevenness of the Apical Constriction in Human Maxillary Central Incisors. J Endod. 2008;34: 157-159.

51. Camargo E, Zapata R, Medeiros P, et al. Influence of preflaring on the accuracy of length determination with four electronic apex locators. J Endod 2009;35(9):1300-1302.

52. Tinaz AC, Alacam T, Topuz O. A simple model to demonstrate the electronic apex locator. Int Endod J 2002;35(11):940-945.

53. Chen E, Kaing S, Mohan H, Ting S, et al. An ex vivo comparison of electronic apex locator teaching models. J Endod 2011;37(8):1147-51.

54. Ibarrola J, Chapman B, Howard J, Knowles K, Ludlow M. Effect of pre-flaring on Root ZX apex locators. J Endod. 1999;25:625-626.

55. Swartz D, Skidmore A, Griffin J. Twenty years of endodontic success and failure. J Endod 1983;9:198-202.

56. Friedman S, Lost C, Zarrabian M, Trope M. Evaluation of success and failure after endodontic therapy using a glass-ionomer cement sealer. J Endod 1995;21:384-390.

57. Shabahang S, Goon W, Gluskin A. An in vivo evaluation of Root ZX electronic apex locator. J Endod 1996;22(11):616-618. 
58. Carvalho de Vasconcelos B, Chaves R, Vivacqua-Gomes N, et al. Ex Vivo Evaluation of the accuracy of electronic foramen locators in root canals with an obstructed apical foramen. $J$ Endod. 2015;41(9): 1551-1554.

59. Ebrahim A, Wadachi R, Suda H. In vitro evaluation of the accuracy of five different electronic apex locators for determining the working length of endodontically retreated teeth. Aust Endod J. 2007;33:7-12.

60. Seltzer S, Bender I, Turkenkopf S. Factors affecting successful repair after root canal therapy. J Am Dent Assoc. 1963;67:651-662. 


\section{Appendix}

Difference (mm) between the control length and the PL per EAL device

\begin{tabular}{|c|c|c|c|c|c|}
\hline Tooth & Root ZX & Apex ID & ProMARK & $\begin{array}{l}\text { Endo-Eze } \\
\text { FIND }\end{array}$ & Foramatron \\
\hline 1 & -0.41 & -0.31 & -0.65 & -0.38 & -0.23 \\
\hline 2 & -0.43 & -0.05 & -0.51 & -0.67 & -0.38 \\
\hline 3 & -0.17 & 0.12 & -0.33 & -0.42 & 0.51 \\
\hline 4 & -0.08 & -0.2 & -0.8 & -0.48 & -0.47 \\
\hline 5 & -0.17 & -0.07 & -0.37 & -0.35 & -0.38 \\
\hline 6 & -0.21 & 0.6 & -0.16 & -0.28 & -0.14 \\
\hline 7 & 0.15 & -0.06 & -0.08 & -0.57 & -0.41 \\
\hline 8 & -0.15 & 0.1 & -0.32 & -0.21 & -0.74 \\
\hline 9 & -0.14 & -0.22 & -0.86 & -0.73 & -0.35 \\
\hline 10 & -0.31 & 0.07 & -0.3 & 0 & -0.7 \\
\hline 11 & -0.31 & -0.1 & -0.26 & -0.17 & -0.81 \\
\hline 12 & -0.06 & 0.31 & 0.09 & 0.05 & 0.19 \\
\hline 13 & -0.32 & -0.14 & 0.32 & 0.01 & 0.1 \\
\hline 14 & 0.3 & 0.18 & -0.03 & 0.12 & -0.44 \\
\hline 15 & -0.59 & -0.13 & -0.14 & -0.5 & -0.3 \\
\hline 16 & 0.17 & 0.08 & -0.56 & -0.13 & -0.47 \\
\hline 17 & 0.24 & -0.2 & -0.34 & -0.07 & -0.11 \\
\hline 18 & 0.39 & -0.06 & 0.02 & -0.06 & 0.11 \\
\hline 19 & -0.49 & -0.67 & -0.65 & -0.5 & -0.54 \\
\hline 20 & -0.42 & 0.19 & -0.25 & -0.33 & -0.46 \\
\hline 21 & -0.26 & -0.62 & -0.39 & -0.01 & 0.6 \\
\hline 22 & -0.48 & -0.07 & 0.02 & 0 & 0.05 \\
\hline 23 & 0.63 & -0.15 & 0.25 & -0.3 & 0.22 \\
\hline 24 & 0.26 & 0.12 & 0.17 & 0.22 & -0.22 \\
\hline 25 & 0.35 & 0.18 & 0.42 & 0.12 & -0.03 \\
\hline 26 & 0.22 & 0.19 & 0.42 & 0.23 & 0.36 \\
\hline 27 & -0.44 & -0.58 & -0.26 & -0.18 & -0.64 \\
\hline 28 & 0.33 & 0.03 & 0.01 & -0.08 & -0.45 \\
\hline 29 & 0.04 & 0.41 & 0.18 & 0.04 & -0.05 \\
\hline 30 & 0.39 & 0.21 & -0.16 & -0.09 & -0.41 \\
\hline 31 & 0.42 & 0.73 & 0.4 & 0.68 & 0.81 \\
\hline 32 & -0.31 & 0.33 & -0.73 & -0.62 & 3.88 \\
\hline 33 & -0.19 & -0.41 & -0.64 & -0.48 & -0.2 \\
\hline
\end{tabular}




\begin{tabular}{|c|c|c|c|c|c|}
34 & -0.46 & -0.17 & -0.51 & -0.49 & -0.4 \\
\hline 35 & 0.16 & -0.3 & -0.23 & -0.35 & -0.45 \\
\hline 36 & -0.33 & 0.41 & -0.08 & 0.17 & -0.01 \\
\hline 37 & -0.65 & -0.46 & -0.67 & -0.64 & -0.31 \\
\hline 38 & -0.06 & 0.12 & -0.36 & 0.08 & -0.21 \\
\hline 39 & 0.1 & 0.05 & 0.22 & 0.2 & -0.11 \\
\hline 40 & -0.59 & -0.28 & -0.39 & -0.29 & -0.41 \\
\hline 41 & 0.25 & 0 & 0.36 & 0.08 & 0.13 \\
\hline 42 & 0.14 & -0.45 & 0.15 & 0.2 & -0.29 \\
\hline 43 & -0.07 & 0.02 & -0.32 & -0.54 & -0.43 \\
\hline 44 & 0.31 & 0 & -0.33 & -0.84 & -0.29 \\
\hline 45 & 0.1 & 0.15 & -0.21 & 0.05 & -0.43 \\
\hline 46 & -0.03 & -0.12 & -0.06 & -0.37 & -0.53 \\
\hline 47 & 0.36 & -0.07 & -0.69 & -0.58 & -0.7 \\
\hline 48 & 0.19 & 0.24 & -0.16 & 0.08 & -0.12 \\
\hline 49 & 0.04 & -0.04 & -0.09 & 0.05 & -0.26 \\
\hline 50 & -0.12 & -0.07 & -0.25 & -0.7 & 0.05 \\
\hline
\end{tabular}

Measurement (mm) from $\mathrm{AC}$ indicator to $\mathrm{MF}$

\begin{tabular}{|c|c|c|}
\hline Tooth & EAL & $\mathrm{mm}$ to MF \\
\hline 51 & 1 & -0.48 \\
\hline 52 & 1 & -0.26 \\
\hline 53 & 1 & -0.08 \\
\hline 54 & 1 & -0.62 \\
\hline 55 & 1 & -2.01 \\
\hline 56 & 1 & -0.61 \\
\hline 57 & 1 & -0.88 \\
\hline 58 & 1 & -0.45 \\
\hline 59 & 1 & 0.48 \\
\hline 60 & 1 & -1.21 \\
\hline 61 & 2 & -0.3 \\
\hline 62 & 2 & -0.01 \\
\hline 63 & 2 & -0.01 \\
\hline
\end{tabular}




\begin{tabular}{|c|c|c|}
\hline 64 & 2 & -4.35 \\
\hline 65 & 2 & -0.41 \\
\hline 66 & 2 & -0.23 \\
\hline 67 & 2 & -0.23 \\
\hline 68 & 2 & -0.16 \\
\hline 69 & 2 & -0.36 \\
\hline 70 & 2 & -0.34 \\
\hline 71 & 3 & 0.37 \\
\hline 72 & 3 & -0.28 \\
\hline 73 & 3 & -0.23 \\
\hline 74 & 3 & 0.27 \\
\hline 75 & 3 & -0.47 \\
\hline 76 & 3 & -0.39 \\
\hline 77 & 3 & 0.22 \\
\hline 78 & 3 & 0 \\
\hline 79 & 3 & -0.92 \\
\hline 80 & 3 & 0.25 \\
\hline 81 & 4 & 0.48 \\
\hline 82 & 4 & -0.51 \\
\hline 83 & 4 & 0 \\
\hline 84 & 4 & -1.06 \\
\hline 85 & 4 & -0.16 \\
\hline 86 & 4 & -0.63 \\
\hline 87 & 4 & -0.53 \\
\hline 88 & 4 & -0.71 \\
\hline 89 & 4 & 0.33 \\
\hline 90 & 4 & -2.81 \\
\hline 91 & 5 & 0 \\
\hline 92 & 5 & -0.65 \\
\hline 93 & 5 & -0.18 \\
\hline 94 & 5 & 0.16 \\
\hline 95 & 5 & -0.27 \\
\hline 96 & 5 & -0.91 \\
\hline 97 & 5 & -0.81 \\
\hline 98 & 5 & -0.38 \\
\hline 99 & 5 & -0.65 \\
\hline 100 & 5 & -1.12 \\
\hline
\end{tabular}

\section{EAL Group}

Group 1: Root ZX II

Group 2: Apex ID

Group 3: ProMARK

Group 4: Endo-Eze FIND

Group 5: Foramatron 